ISSN No. 2454 - 1427

CDE

February 2016

\title{
A Comparative Study of Living Conditions in Slums of Three Metro Cities in India
}

\author{
Sugata Bag \\ Email:sugata@econdse.org \\ Department of Economics \\ Delhi School of Economics \\ Suman Seth \\ Email: S.Seth@leeds.ac.uk \\ Economics Division \\ Leeds University Business School \\ \& \\ Oxford Poverty \& Human Development Initiative (OPHI) \\ University of Oxford, UK \\ Anish Gupta \\ Email: anish.brac@gmail.com \\ Bhim Rao Ambedkar College \\ Delhi University
}

\author{
Working Paper No. 253 \\ http://www.cdedse.org/working-paper-frameset.htm
}

\author{
CENTRE FOR DEVELOPMENT ECONOMICS \\ DELHI SCHOOL OF ECONOMICS \\ DELHI 110007
}




\title{
A Comparative Study of Living Conditions in Slums of Three Metro Cities in India*
}

\author{
Sugata Bag ${ }^{\dagger}$, Suman Seth ${ }^{\ddagger}$ and Anish Gupta ${ }^{ \pm}$
}

\begin{abstract}
Urban population in India has been rising rapidly as millions of migrants are moving to urban areas aspiring for higher earning and better living. The number of urban poor is also growing and a significant number of these poor find spaces in slums and continue to struggle for better living standards. Improving their conditions call for significant efforts from the governments for better policy designs. However, better policy design requires understanding the commonalities and differences across slums within and between cities. In this paper, we conduct a comparative study of representative slums across three largest metro cities in India through primary surveys. We find certain characteristics, such as large average household size, poor housing quality, low female labour market participation and high school enrolment rates among children, to be common across and within three cities. Our study however reveals crucial differences between the cities in the demographic pattern of migration and its temporal element. And that in turn brings out considerable heterogeneity among different groups within slums of each cities with respect to living standards, access to civic amenities like sanitation facilities and drinking water. Moreover, there exists major cross-city differences in adult literacy rates across gender, consumption pattern, and subjective wellbeing. Overall, we find that slums in Mumbai on average perform much better in various living condition and social indicators than slums in Delhi and Kolkata.
\end{abstract}

Key Words: Living conditions in slums, primary household survey in slums, Kolkata, Delhi, Mumbai, migration, multidimensional material deprivation.

JEL Classification: O1, O18, R2, I3

\footnotetext{
* We acknowledge excellent research assistance by Alreena Pinto, Tanu Gupta, Shruti Issar, Protyusha Banerjee, Harjyot Kaur, Pramod Dubey at the Centre for Development Economics, Delhi School of Economics. We would like to thank Amulya Sahoo, Atanu Acharya, Jyoti Prakash Verma, Rajesh Nath, Sumit Bhaduri for their supervising effort during the various phases of the survey; the enumerators who were students of the University of Calcutta and Jadavpur University in Kolkata, the Delhi School of Economics and B. R. Ambedkar College in Delhi, and St. Xaviour's College and Ambedkar College, Wadala in Mumbai. We thank the Commissioner of Kolkata Municipal Corporation, the Director of Mission Convergence, Delhi for sharing their slum level data with us. This paper is an outcome of the project titled "Exploring the dimensions and dynamics of Indian urban poverty: Multidimensional and Political aspects" that is funded by European Commission under a five year term global research project called 'NOPOOR'. We are grateful for valuable comments from the participants at the 2015 Development Studies Association Conference at the University of Bath, UK. All errors in this paper remain ours.

$†$ Department of Economics, Delhi School of Economics, University of Delhi, Delhi-110007, India and Centre for Development Economics, Delhi School of Economics, India, +91 112700 8115, sugata@econdse.org.

* Economics Division, Leeds University Business School, Maurice Keyworth Building, Leeds, LS2 9JT, UK, and Oxford Poverty \& Human Development Initiative (OPHI), University of Oxford, UK, +44 113343 2629, S.Seth@ leeds.ac.uk.

${ }^{ \pm}$Bhim Rao Ambedkar College, Delhi University, New Delhi, India, anish.brac@gmail.com.
} 


\section{Contents}

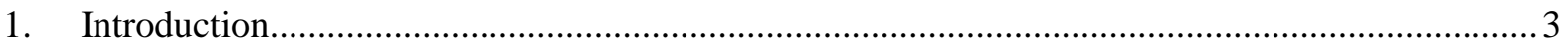

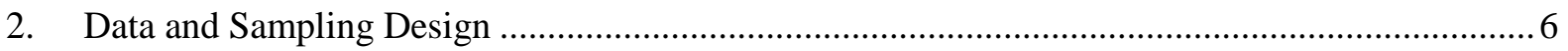

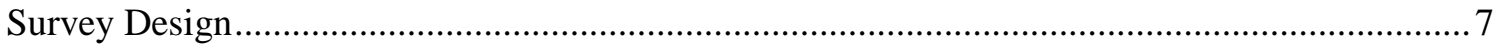

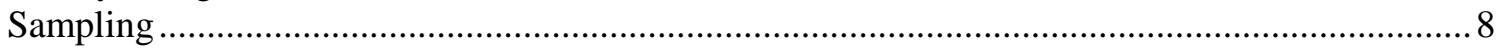

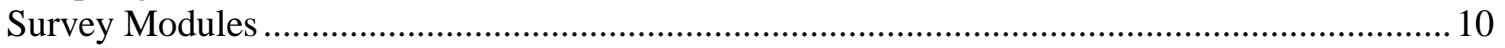

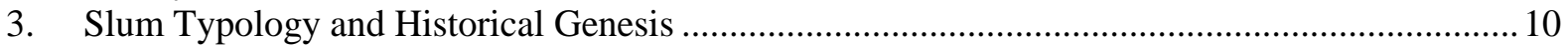

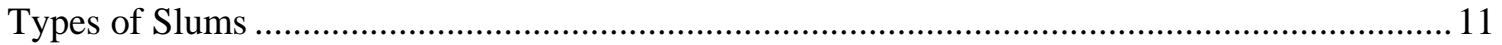

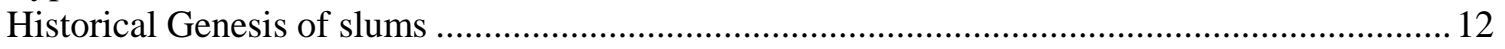

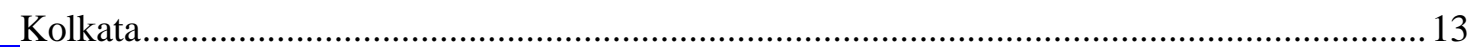

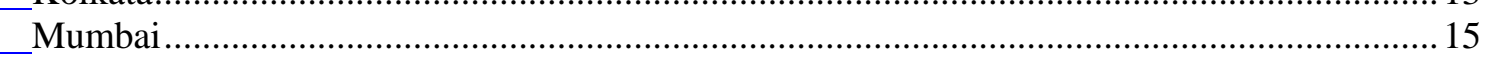

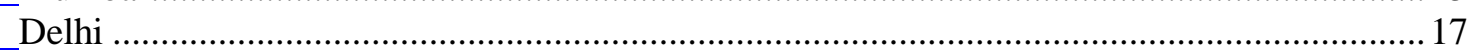

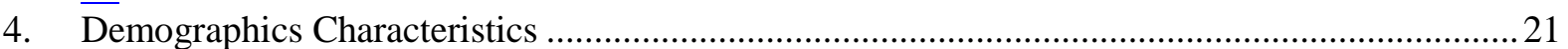

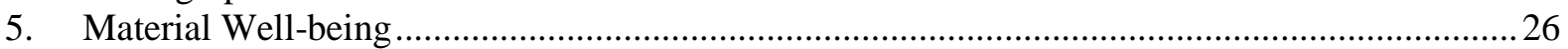

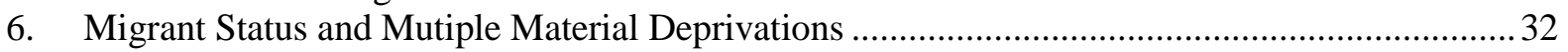

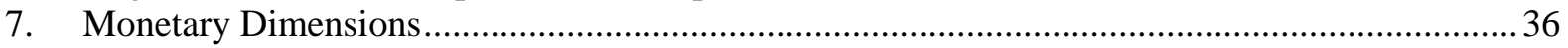

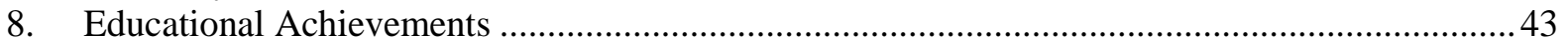

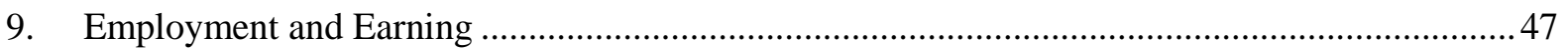

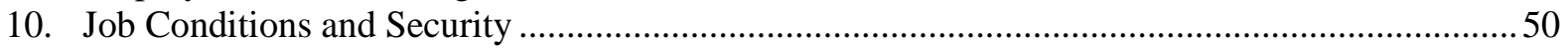

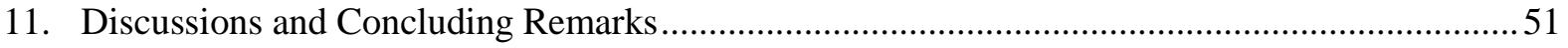

Appendix A: The distribution of sample household across different strata in Three Cities .................57

Appendix B: Holding Status of Various Government Issued Cards in Slums of Three Cities .............57

\section{List of Tables}

Table 1: Migration Status of Household Heads by the Region of Origin .............................................22

Table 2: Decadal Distribution of Migrated-Heads in Slums of Three Cities........................................24

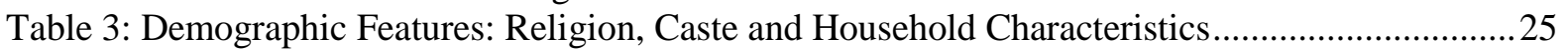

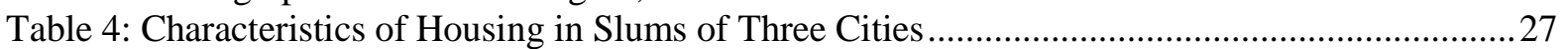

Table 5: Access to Various Housing Facilities in Slums of Three Cities ............................................. 30

Table 6: Possession of Assets by Slum Dwellers in Three Cities....................................................... 32

Table 7: Indicators of Material Deprivation and the Percentage of Households Deprived ................... 33

Table 8: The average material-deprivation score for different cities and migration categories.............35

Table 7: Monthly Per Capita Income, Consumption Expenditure and Inequality .................................38

Table 8: Distribution of Monthly Mean Per Capita Consumption Expenditure across Components ...39

Table 9: Monthly Per Capita Consumption and Median Prices of Cooking Fuel and Grocery Items .. 41

Table 10: Educational Achievement among Adults in Slums of Three Cities......................................4

Table 11: Student Enrolment Rates in Educational Institutions over different age groups ..................46

Table 12: Some Schooling Characteristics for Students in 6-14 Year Age Group ................................47

Table 13: Labour Force Participation Rates, Average Years of Education and Average Incomes across

Age-groups and Genders in Slums of Three Cities............................................................................

Table 14: Education, Wage and Labour Supply by Type of Job Contracts in Slums of Three Cities ..51

\section{List of Figure}

Figure 1: Decadal Migration Pattern of the Surveyed Households in Three Cities..... 23 


\section{Introduction}

Urbanisation of economy is an important aspect of the new global order. Urban areas in every country are turning out to be major centres of economic activity accommodating both formal and informal sectors. The very promises of higher earnings and better living in urban areas draw millions of migrants from rural hinterlands and other settlements to urban agglomerations. However, many of these migrants are not adequately educated or skilled to find their way into the middle or upper stratum of the urban labour force. ${ }^{1}$ They find shelter either in existing settlements or squatters in and around economic hubs within the city limits or form new ones in the outer fringes of cities, which are often referred to as 'slums'. Besides being melting pots for different communities and cultures by providing low cost and affordable housing, the slums are also the sites of a lot of economic activities - workplace and residence are inter-woven. Moreover, the slums also contribute significantly to the economy of cities by being a source of affordable labour supply. However, de Soto (2003) notes that the land and the capital in slum areas are seen as "dead capital", which are productive but cannot be used or leveraged by those who live and work there. The slums are often characterized by acute shortages of housing and basic civic amenities as well as manifest poor socio-economic outcomes. Although these characteristics are not necessarily confined to slums only, the prevalence of these characteristics is found to be certainly accentuated within slums. By no means does this imply that the settlements in slums should be removed from cities. Rather, it is also true that slums are an unfortunate reflection of exclusionary socio-economic policies. Urban policy needs to find ways of integrating slums into the city's settlement system and ensure improvement of the lives of the dwellers of these settlements through access to basic services.

Improving the living conditions of slum dwellers has been an integral part of the global development agenda. An important target of the seventh Millennium Development Goal had been to 'achieve a significant improvement in the lives of at least 100 million slum dwellers by $2020^{\prime} .{ }^{2}$ The proposed eleventh Sustainable Development Goal also calls for making 'cities and human settlements inclusive, safe, resilient and sustainable', where the first target of the goal aims to ensure 'access for all to adequate, safe and affordable housing and basic services, and upgrade slums by $2030{ }^{3}{ }^{3}$ In the year 2000, the total slum population of the developing regions of the world was 760 million, which represented 39.4\% of the total urban population of those regions. Although by 2012, the share of slum population to the total urban population of the developing regions came down to $32.7 \%$, yet the total slum population increased to 863 million (Table 3, UN-HABITAT, 2012). Among the developing

\footnotetext{
${ }^{1}$ Ravallion (2003) in a theoretical model, using Indian data between 1974-1998, shows that the poor tend to urbanize faster. 2 The operational definition of slum is an area the where individuals reside in housing with one or more of the following conditions: inadequate drinking water, inadequate sanitation, poor structural quality/durability of housing, over-crowding, and insecurity of tenure (UN-HABITAT, 2003).

${ }^{3}$ The information has been accessed in May 2015 at https://sustainabledevelopment.un.org/sdgsproposal.html.
} 
regions of the world, the share of urban population living in slums is highest in Sub-Saharan Africa, a staggering $61.7 \%$. The next largest share of urban population living in slums was Southern Asia, where nearly $35 \%$ of the urban population was living in slums.

The slums of India were predominantly created when large numbers of individuals or families were drawn, moved or brought to the urban centres in search of better economic prospects either because of the huge disparity between urban and rural income levels or to meet the shortage of labour. Metro cities have been the preferred destinations for generations of rural Indians. These urban centres are neither geared to nor governed in a manner that can accommodate or reject such an influx of people. Residential areas in cities generally do not provide accommodation or employment. As a result, the migrants find accommodation close to their place of work in unorganised dwellings - the slums, which have become common features in most Indian cities like the cities in other parts of the world.

Slums have distinct characteristics than the rest of the city dwellings, with tiny-roofed congested structures/huts made of brick, earth or wattle ${ }^{4}$, and are generally deprived of basic civic amenities. According to the $69^{\text {th }}$ round survey of the National Sample Survey Office (NSSO) conducted on slums across India in 2012, 31\% of slums had no latrine facility, $31 \%$ of all slums had no drainage facility, $27 \%$ of all slums had no garbage disposal arrangement and the primary approach road to the slum mostly remained waterlogged because of rainfall in $32 \%$ of all slums. The 2011 Indian census data reveal that the achievements of slum dwellers are much worse in various living-condition indicators than the overall urban averages. According to the census 2011,68\% of urban households lived in houses with good conditions, while the corresponding figure was $57 \%$ in slums. In urban areas, $77 \%$ of households had access to television and $19 \%$ of households had access to computers; whereas the corresponding access rates were only $70 \%$ and $10 \%$, respectively, in slums. In 2011, $68.4 \%$ of urban residents had access to banking services. The corresponding figure in slums for the same year was merely $56.9 \% .^{5}$ In $2011,85 \%$ of the urban population was literate; whereas only $77 \%$ were literate in urban slums. Note that the overall urban population includes slum dwellers and given that in Delhi, Mumbai and Kolkata, a third to half of the metropolis' population lives in slums, the differences that we present would be much wider between slum and non-slum residents in these three cities.

It is not necessary that the totality of the urban poor is living in the slums only, but definitely a dominant section of 'vulnerable and/or poor' population of a city finds their way into the slums. Slum dwellers are subject to marginalization by various socio-economic forces; but by no means, they are a

\footnotetext{
4 Wattle is a framework made of sticks and twigs; hence the term in building wattle-and-daub, for earthen walls where earth is applied over the wattle.

${ }^{5}$ The access to banking service figures may have improved in both slum and non-slum areas following the introduction of Prandhan Mantri Jan-Dhan Yojna in August 2014 (http://www.pmjdy.gov.in/ accessed on October 3, 2015).
} 
homogenous group. They vary widely with respect to their shelter requirements. The deciding factors could be the extent of consolidation in the city, location sensitivity, physical requirement, ability to pay and earn as well as tenure security. These three metropolitan cities, concerning our studies, are characterized by high population density, which accentuated by the fast growth of slums, may severely challenge the urban infrastructure, environment, social health and harmony. From a social planning perspective, it is possible to think about their social development and that requires in-depth analysis of their living conditions and the hazards/factors of marginalisation faced by these people.

Improving the living conditions of slum dwellers calls for both substantial and comprehensive policy design, ${ }^{6}$ but it is difficult in the absence of proper understanding of the characteristics of slums and its inhabitants. The slums, in general, across the world, have certain common attributes that differentiate them from other parts of urban areas as well as rural areas, however, there can also be significant 'inter-city' and 'intra-city' differences in their characteristics. The slums that are 'recognised' by local government bodies benefit from various public interventions, while the 'unrecognised' slums do not. Some slums are on private lands; whereas, others are on lands owned by various government bodies. Some slums are located in the heart of the city within the close proximity of developed residential areas, but others are in the periphery along the industrial corridors or railway tracks or sewage drainages or by the side of water bodies. Some slums in certain cities are more old, organized, and have reached a saturation limit; whereas, the slums in other cities are still growing. There are also differences in governmental approaches to slum redevelopments (owing to property rights issue) or interventions through welfare schemes across cities. In certain cases, slums have been removed and relocated to resettlement colonies, whereas in other cases existing slums are redeveloped in the same place. In the development economics literature, studies are abound that focus on slums within cities to explain rapid urbanization and its ills. ${ }^{7}$ However, there is, unfortunately, dearth of comparative studies on slums across cities. ${ }^{8}$ A comparative study may be useful in pointing out the commonalities and the differences between slums across as well as within the cities, which may also help policy makers to design more targeted and effective policy options.

In this paper, we conduct a comparative study of slums (and resettled slums) within and across three metropolitan cities of India - Delhi, Kolkata, and Mumbai through primary household surveys. This

\footnotetext{
${ }^{6}$ Marx, Stiker and Suri (2014) argue that there has not been enough theoretical and empirical economic research about how to address various public policy challenges posed by slums in low-income countries.

${ }^{7}$ Swaminathan (1995) considered poverty and deprivation among pavement dwellers and households living in a designated slum area and concluded that a comprehensive approach considering housing and living conditions looking beyond income is required; Kumar and Aggarwal (2003) studied the patterns of consumption and poverty in Delhi slums; Mitra (2005) examined the standard of living of Delhi's slum population and analyzed the determinants of standard of living; Banerjee, Pande and Walton (2012) studied deprivation, preferences and political engagement among the urban poor in Delhi; Mallik (2014) study gender inequality in literacy and school education in slums of Kolkata.

${ }^{8}$ Kundu and Sarangi (2007) studied the migration pattern and employment status in urban centres using the Indian NSS $55^{\text {th }}$ round dataset, but did not conduct any comparative study across slums; Hina (2013) studied living conditions across two different slums but both within Delhi.
} 
study aims to bring out new comparative insights about the living conditions of the slum dwellers. Although the main thrust of this study is to analyze the differences of living conditions of the slum dwellers across the cities, we also recognize the fact that there exists considerable heterogeneity in living standards among the various groups of dwellers within slums of each city. And admittedly, there could be several ways of identifying these groups within a city and capture the heterogeneity in living conditions among them - e.g. ethnic or provincial identities of migrant groups or temporal elements of migration pattern or settlement/resettlement pattern and so on. Consequently, we choose to depict this heterogeneity within city with two research questions. First: Do housheolds living in rehabilitated colonies (or, registered slums) differ in significant ways from those living in unregistered/unrecognized slums? Second: How do more recent migrants fare compared to the migrants from earlier decades? To deal with the first question, we compare the living conditions in Resettlement Colonies of Delhi with other unrecognized slums of Delhi and other cities; and for the second one, we segregate the slum dwellers of each city into three categories on the basis of their duration of stay in the city. We find evidences of differences as well as similarities.

Our choice of these three cities is interesting for two main reasons. First, these three cities have the largest share of slum population in India: Mumbai being the largest followed by Delhi and then Kolkata. Of the steady increase in slum population in India from 52.4 million in 2001 to 65.5 million in $2011,{ }^{9}$ a significant share has been absorbed by these three cities and together these three cities allow us to collect samples covering over ten million slum dwellers. Second, each city being 9001250 miles away from each other, allows us to capture crucial geographical, cultural and preferencebased differences.

The paper is structured as follows. We devote section 2 discussing the historical backgrounds of the slums in three cities. In section 3, we describe data, survey design and survey modules. In sections 45, we present comparative results based on demographics characteristics, material well-being. In section 6, we analyse the multidimensional material-deprivations of slum dwellers in each city by classifying them into different migration groups. In sections 7-9, we analyse income and consumption patterns, educational achievements, employment and earnings. Finally, in section 11 we discuss our findings, their policy implications and provide concluding remarks.

\section{Data and Sampling Design}

Our primary household survey collects representative samples through stratified sampling from slums of the municipal corporation areas of three metro cities of India: Delhi, Mumbai and Kolkata under

\footnotetext{
${ }^{9}$ See the Primary Census Abstract for Slums of India, 2011 (pp. 12). Note that the figures on slum dwellers obtained from the India Census are different from what is reported in UN-HABITAT (2012) because of the difference in their definitions. For a relevant discussion, see Chapter III of GoI (2010).
} 
the project titled "Exploring the dimensions and dynamics of Indian urban poverty: Multidimensional and Political aspects", which has been funded by the European Commission under a five-year term (2012-2016) global research project "NOPOOR". The survey collects more detailed slum-specific information than what is available from the census and other nationally representative surveys. ${ }^{10}$ The limitation of analyses using census is that the census does not provide detailed information on a large number of variables; whereas the national and international surveys that are nationally representative does not collect enough information that are specific to slums. ${ }^{11}$

\section{Survey Design}

For our sample survey, we adhered to the most common method of selecting households using twostage stratification. In the first stage, the municipal corporation areas of each of the three cities were stratified according to the largest possible administrative divisions that are available through official documents. In case of Kolkata, the stratification was done at the borough level, which means that each borough represents a stratum. In case of Mumbai, the stratification was conducted at the ward level and for Delhi at the revenue-district level. In the second stage, first a collection of slums were randomly selected within each stratum (borough/ward/revenue districts) and then the households were selected randomly to be interviewed from each of the selected slums.

In the first stage, the number of households to be interviewed from each stratum was determined through proportional sampling with the requirement that at least thirty households should be interviewed from each stratum. In order to match the limited budget for the survey, however, in the second stage, we decided to interview at least eight households and on average fifteen households from each of the selected slums with each stratum. ${ }^{12}$ This restriction thus increased the likelihood of selecting a larger number of slums within bigger stratum.

For designing our survey, we relied on various datasets either available in the public domain or acquired through different government agencies. It is worth mentioning that when we were designing the survey there was no uniform slum specific dataset available for all the three cities. The census data for 2011 on slum population was only partially available at the aggregated level, whereas the Census data for 2001 was out dated. Many civic bodies have had already updated their databases either in line with Census 2011 or through independent surveys on their own in the interim period. For the purpose

\footnotetext{
${ }^{10}$ Recent studies have questioned whether the current data and indicators are fit for the purpose of monitoring the progress of urban poverty and calls for better and more rigorous data collections (Lucci and Bhatkal, 2014).

${ }^{11}$ According to GoI $(2011$, p.6), "The National Sample Survey Organization (NSSO) surveys provide the base for estimating poverty levels and gaps; the base also permits an analysis of the pattern of consumer expenditure. These surveys, however, do not shed light on who the urban poor are, what they do, and where they live. Absence of such basic information represents a serious handicap in designing poverty alleviation programmes that can be focused on them."

${ }^{12}$ It is worth noting that footpath dwellers are treated differently from slum dwellers by most civic authorities, Census and NSSO. While Delhi Urban Shelter Improvement Board (DUSIB) in its websites maintains a list of daily attendees in various night shelters, it does not provide any data on footpath dwellers. Kolkata and Mumbai civic bodies also fail on both counts.
} 
of the survey design (both stratification at the first stage as well as the selection of slums at the second stage) for Kolkata, we acquired the slum level information from 'Bustee data' that was compiled by the Kolkata Municipal Corporation in March 2008. For Mumbai, we have used two datasets: the ward-wise population distribution from the Mumbai Human Development Report (2009) in order to accomplish proportional sampling across wards at the first stage and the slum-wise data compiled by the Slum Rehabilitation Authority (SRA) of Mumbai in order to select the slums at the second stage. ${ }^{13}$ Both these sources used Census 2001 slum data as their basis. In Delhi we decided to cover two types settlements by the poor - squatters clusters and resettlement colonies. Thus, we have drawn two different survey designs and used two types of datasets - the list of Jhuggi Jhopri (squatters) clusters and the list of Jhuggi Jhopri Resettlement and Relocation colonies. Both of the datasets were obtained from the website of Delhi Urban Shelter Improvement Board (hereafter, DUSIB). ${ }^{14}$

\section{Sampling}

The proposed sample sizes for the three cities were determined by the size of the total slum population and on the degree to which regional or other special subsamples are required. Our proposed sample sizes were 800 households from the slums of Kolkata, 1,250 samples from the slums of Delhi; and 1,200 samples from the slums of Mumbai. The actual distribution of samples collected from different strata within each city is listed in Appendix A.

Kolkata: The area under the Kolkata Municipal Corporation is divided into 15 boroughs that are the largest possible administrative divisions. Seven of the fifteen boroughs had small fraction of slum population and hence, at least 30 samples from each of these seven boroughs were collected. We have interviewed 808 households from slums in Kolkata and the interviews were conducted in two phases. In the first phase ranging from end-May to mid-June 2013, 600 households were interviewed from 47 slums in ten boroughs: borough numbers 1-9 and borough number 15. In the second phase, the survey was conducted during the first week of October in 2013, when 208 households were interviewed from 16 slums from the rest of the five boroughs.

Mumbai: The area under the Municipal Corporation of Greater Mumbai is divided into 24 wards. We have interviewed 1,228 households from slums in Mumbai and the samples were collected in two main phases and a minor third phase. In the first phase, between mid-May and mid-June 2013, 600 households were interviewed from 48 slums in 23 wards. In the second phase lasting from mid-May to mid-June 2014, a further 603 households were interviewed from 44 slums in 22 wards. Finally, in

13 The slum-wise data compiled by the Slum Rehabilitation Authority (hereafter, SRA) have been accessed in February 2012 at http://sra.gov.in/data/Census\%20Data/Ward_slum.htm.

14 The list of Jhuggi Jhopri clusters has been accessed at http://delhishelterboard.in/main/?page_id=3644 in February 2013 and in February 2014 at two different stages of our survey. The list of Jhuggi Jhopri Resettlement and Relocation colonies has been accessed at http://delhishelterboard.in/main/?page_id=86 in August 2014. 
order to accommodate some shortfalls in the last two surveys, in the brief third phase in October 2014, we surveyed 25 households from 4 slums in 4 wards. Given that the type of land-ownership on which the slums are built plays an important role affecting the socio-economic structures of the slums, our effort was to ensure that the overall sample represents the type of land-ownerships. ${ }^{15}$ It is worth mentioning that the authorities of Mumbai envisaged into slum redevelopment programme since 2000s, and during our survey we have found resettlement pockets ${ }^{16}$ (rather buildings) by the side of existing slums. For the sake of capturing the diversity, the residents of these buildings (as these people used to live in slum at that location) were also included in the survey. Samples were collected from 23 wards because one ward (Ward C) did not have any slum dweller. Also, the proportion of total slum population was low in seven wards and so at least 30 samples were collected from these seven wards.

Delhi: The Delhi Municipal Corporation area, which comprises of 4 municipal authorities, is divided across 11 revenue districts. ${ }^{17}$ In Delhi, we considered two major classifications of slums. ${ }^{18}$ One classification consisted of the collection of squatter settlements - referred as 'Jhuggi Jhopri Clusters'. The other classification included the 'resettlement colonies', which were developed under the schemes for 'resettlement of Jhuggi Jhopri clusters, and 'relocated Jhuggi Jhopri Clusters'. ${ }^{19}$ Jhuggi Jhopri Clusters are scattered all over the city across all eleven districts; whereas 47 resettlement colonies and 15 relocation sites are spread across seven of the eleven districts. We have interviewed a total of 1,295 households from the slums in Delhi, of which 864 households were from Jhuggi Jhopri Clusters and 431 households were from resettlement and relocation colonies. Samples were collected

\footnotetext{
${ }^{15}$ The majority of slums in Mumbai are built on government lands owned by the Central or State Governments, or the Local Bodies like Municipal Corporation of Greater Mumbai (also known as Brihanmumbai Municipal Corporation or BMC), Maharashtra Housing \& Area Development Authority (MHADA); some slums also exist on the lands of private owners. We tried to ensure that different types of land ownerships are represented in our sample.

${ }^{16}$ These are mostly multi-story building/s (known as Slum Rehabilitation Authority (SRA) buildings) constructed under SRA provisions towards redeveloping slums in the same locations where erstwhile slum existed (in-situ rehabilitation). The original dwellers of those slums were rehabilitated in these buildings. Please note that at the time of survey design we could not obtain well-documented information on the exact proportion of population living in Resettlement Colonies in Mumbai. Further, it is not clear whether these buildings are also legally part of slums.

${ }^{17}$ The four municipal authorities of Delhi are New Delhi Municipal Council, North Delhi Municipal Corporation, East Delhi Municipal Corporation and South Delhi Municipal Corporation. The three of these four municipal corporations - North, East and South - were created in 2012. Prior to 2012, the municipal corporation areas comprised of nine revenue districts. Delhi had 9 districts prior to October 2013, later two new districts (Shahdara and South-East Delhi) were curved out and at present the four municipal corporation areas are divided into 11 revenue districts.

${ }^{18}$ For detailed references on the definitions and distribution of slums in Delhi municipal corporation areas, see City Development Plan Delhi, Government of Delhi (2006, pp. E-5) [hereafter, CDP 2006]. This is the only government document that acknowledges and classifies slums of Delhi in 4 categories: (1) Jhuggi Jhopri (JJ) Clusters or Squatter settlements (this is the only category that is at present recognized as slums by the Delhi Government and the Census 2011 authority follows that); (2). Notified Slums in Old Walled City area and in Nizamuddin area (but CDP 2006 does not mention about the number of tenements or proportion of slum population, further since Census of 2001 these areas are also not considered as slum); (3) Resettlement Colonies (there were total 44 such colonies according to DEP 2006; but as per DUSIB website, as accessed in March 2014, number of such colonies stands at 47); (4) Relocation Colonies (CDP Delhi 2006 mentions about 11 of such colonies, but the number has increased to 15 post 2006).

19 The first scheme of resettlement of Jhuggi Jhopri clusters started in 1961 and carried on until 1977. In this period, 45 Resettlement colonies were created. Another scheme of resettlement of Jhuggi Jhopri clusters started in middle of 1990's and carried on until 2010. These newly rehabilitated colonies are referred as "Relocation colonies". We could not substantiate the slum population figures in Walled City area (CDP Delhi 2006 loosely mention about 3 million population, but does not even indicate on slum proportion), so despite doing several reconnaissances in that area we could not do the survey.
} 
in three phases. In the first phase lasting from the beginning of September till the end of October 2013, 401 households were interview from 27 slums of Jhuggi Jhopri Clusters across 11 districts. In the second phase between March and June 2014, 431 households were interviewed from 27 slums within resettlement and relocation colonies across seven districts (other districts don't have these colonies). Finally, in the third phase between August and September 2014, a further 463 households were interviewed from 30 slums of Jhuggi Jhopri Clusters from 11 districts.

\section{Survey Modules}

We designed our survey questionnaire on the basic framework of the latest round of NSSO household survey and slum particulars, and customized it further to incorporate more variables so as to capture the intrinsic slum characteristics that we learned from our pilot survey. Our objective has been to create a rich data source on economic behaviour to establish its links to better policymaking. So the questionnaire aims to capture information at two levels: the household level and the individual level.

Household level information: We captured information on religion, caste, ration card holding status, Aadhar card holding status, type of housing and its ownership details, access to toilet and its type, sources of water, electricity, migration status, access to government schemes, durable and occupational assets ownership, land \& house ownership details and related income, cooking fuel type and expenditure, monthly consumption details of grocery items through Public Distribution System and other sources and baby-food items; weekly expenditures on vegetable items and non-vegetarian items, expenditure on intoxicants; details on inflow and outflow of remittances, lending and borrowings; family health related details and political aspects of livelihood details.

Individual level information: We capture details on age, gender, marital status, the age at marriage, status of work, literacy status, educational attainment, schooling details and drop out reasons, migration details; employment details including monthly income, past occupations; savings account at bank and post office, insurance holding; health related aspects like disability, chronic illness, child health; motherhood and child mortality.

\section{Slum Typology and Historical Genesis}

Before presenting our findings, in this section we outline the typology and history of slums in the three cities, which shows the different timelines and patterns of evolution of these slums. ${ }^{20}$

\footnotetext{
${ }^{20}$ The ensuing discussion on the history of Kolkata slums is based on Kundu (2003), Schenk (2010) and the portal "Life in Calcutta's Urban Slums" by Ramaswamy, V., that of Mumbai is heavily drawn from Risbud (2003) and the portal "Slums of Mumbai" (by Tata Institute of Fundamental Research, accessed at http://theory.tifr.res.in/bombay/history/slums.html in January 2015), and that of Delhi from Basu (1988), Dhar Chakravarti (2001), Dupont (2008), Priya (1993) and Singh (2009).
} 


\section{Types of Slums}

The general term slum can refer to both 'bastis' and 'squatter' settlements. The Basti (a local term used in all three cities) settlements are the tenements created by local landlords or their agents to provide shelters to migrant industrial workers on the basis of a (long term) lease agreement (called Thika or Pagri). ${ }^{21}$ The Squatter settlements (local terms are Jhupri in Kolkata, Zopadpatti in Mumbai, Jhuggi Jhopri in Delhi) are illegally occupied (either on private or government lands) clusters of quasi-permanent habitation along the canals, railway tracts, or roads or any previously vacant degraded lands. Schenk (2010) notes that dwellers in squatters often live in the anticipation of potential evictions - though of different degrees - depending on the settlements' location and their political affiliations.

Legally notified slums are those that have been designated as slums under the Slum Areas Improvement and Clearance Act (1956). Designated slum areas include settlements with varying range of legality and degree of deficiency of services. From the legal viewpoint, slums are primarily classified into two categories: (a) registered or authorised or notified (mainly bastis) and (b) unregistered or unauthorised (mainly squatters). This typology is important as each of the different type of residential settlements has implications in terms of entitlements to basic services. Registered slums enjoy some legal status, conferred by the municipal authorities, that gives them some security about their tenure. It also helps them in accessing certain civic facilities like water supply, electricity connection, latrine-sanitation etc. Unregistered slums or squatters are illegal, the dwellers of these settlements are often bereft of even these minimum civic services, and are, moreover under constant threat of evacuation.

There is one more type of habitation pattern of the poor in Indian cities that are called Resettlement Colonies. It is worth noting that the resettlement colonies are generally not considered as slums by the local governments and Census authorities. These colonies are built by the government-designated authorities to rehabilitate residents evicted (mainly) from squatter settlements on public land. There are two distinct patterns of rehabilitation programme pursued by the government authorities 'displace and rehabilitate with registered leasehold' and 'in-situ rehabilitate with a delayed freehold'. In the first case, resettlement colonies are created (by allotting plots on long term lease, without the rights to sale) in the periphery of the city by breaking community ties and removing residents from their sites of employment and residency. In case of 'in-situ' resettlement, an existing slum is being

\footnotetext{
${ }^{21}$ Examples of this type of settlements are Old Bastis in Kolkata, Chawls in Mumbai and Katras in Old Delhi. Thika Tenancy Act 1949 defines Thika Tenant as any person who held land under written lease and erected any residence or any construction for business purpose on such land. A "Pagri" or "Pagdi" system has similar bearings. It means that a landlord lets a 'tenant' to use his/her property - forever in most cases - after receiving a "pagri", which is an amount slightly below the prevailing market price. In return, the tenant pays a small amount of monthly rent and stays on the premise for years without any fear of eviction. The property remains in landlord's ownership, who continues to pay property tax.
} 
redeveloped into a multi-story compound and the original settlers are resettled into flats in these buildings along with a 'delayed freehold' 22 agreement. The first type of rehabilitation is commonly pursued in Delhi until recently, whereas the second type is dominant in Mumbai.

According to UN-HABITAT $(2012,2014)$ tenure insecurity is an important aspect of slum dwellers and their marginalisation, but this is not considered as an important parameter by the Slum Act of 1956 or by the authorities of Census and NSSO while declaring any area as slum. Having a legally recognised foothold (in the form of a registered slums or rehabilitated settlements vis-à-vis squatters) in the city empowers and enables the slum dwellers to have a formal access to basic services. This certainly brings some stability in their life, which cannot be discounted. However, the diversity of plight of people living in these three types of settlements cannot be embodied only through the distinction between these three types of settlements. People in either type of slum settlements - both are overpopulated and unhygienic - mostly manage their lives with inadequate amenities. In the context of Delhi resettlement colonies, Sheikh et. al. (2014) note that the disruption created by resettlement procedure by breaking ties of livelihood has however often not been adequately balanced by improved services or proper security of tenure. Residents of these resettlement colonies still maintain almost similar, poor access to basic services, their property rights remain severely limited, and sometimes they are not legally guaranteed protection from another eviction. Thereby, slums need to be identified, classified and prioritized on the basis of tangible parameters - especially on the basis of living conditions and not on the basis of their legal standing. This is important and should be recognised by the government authorities so that the improvement packages are appropriately designed and subsidies are correctly targeted.

\section{Historical Genesis of slums}

Incidentally these three cities perhaps house some of the oldest slum settlements in India and the existence of slums can be traced to the colonial period. The historical patterns and growth of slums in Kolkata and Mumbai are very similar; however, Delhi follows a completely different path. Both in Kolkata (the-then Calcutta) and in Mumbai (erstwhile Bombay), slums came into existence in the colonial period because of large-scale rural-urban migration that was closely linked to the industrialization process. And the slums continue to grow, even in the post independence era, as a response to steady flow of migration and growth of population far beyond the existing housing capacity. But in Delhi, the initial proliferation of slums was related to a historical transformation process, which was linked to the change of rulers and their approaches to city formation and community management from time to time.

22 'Freehold (Individual)' status confers a ownership in perpetuity, that allows outright sale by the owner; whereas 'Delayed Freehold' status is a conditional ownership, where the title is granted either on the completion of payments or when developments have been completed or after the completion of residency of certain period or a combination of the three. 


\section{Kolkata}

\section{Colonial Phase: Birth and growth of slums}

Under the British rule, the metropolis grew over the years around the Port as a major trading and administrative hub. The very first instances of slums were created by the ghettos of servants who came to serve their imperial masters and their families. But these were only fixtures in the city. However, Colonial Calcutta observed rapid industrialisation since the middle of the $19^{\text {th }}$ Century. First it started in northern Calcutta with jute/textile mills and paper mills during 1870s; later in the centraleast region of Calcutta, chemical and pharmaceutical plants came up during 1890s, followed by rubber and glass factories in the same region, and later tanning and shoe-making industries (Furedy, 1982). The industrialisation process and the simultaneous proliferation of services like railways, postal services, banking, and docking facilities in port area, required large number of labourers. Labourers from various hinterlands of neighbouring northern and eastern India moved (in some cases were brought as well) to Calcutta for jobs in these industries and services. According to Furedy (1982), "It was estimated that slums grew to cover a third of Kolkata over the next forty years... Employer location continued to dictate the locations of slums through the $20^{\text {th }}$ century".

The geo-spatial growth of habitation was quite irregular. Settled migrants' low incomes ensured that they became spatially immobile, thus proximity to a work place was essential to a slum-dweller. The mills and factories did not provide any attached housing which inevitably led to the establishment of an arrangement, as close as possible to the factories, that eventually led to a unique three-tier tenurial structure - a landlord, a middleman and migrant tenants. A landlord would, typically, rent out vacant plots under his ownership to members of his retinue, who in turn built a large number of huts on the plot. Rooms in the huts were rented out to the labourers.

Apart from this, during the British period, there existed two other types of slums. One type called "thika tenant slums" where the slum dwellers took possession at a fixed rent and constructed their shanties (houses). Other types of slums were those constructed by zaminders (landowners) themselves and let out to the migrant industrial workers (Kundu 2003). In local terms, these settlements are called 'basti'. However, these slums (i.e. bastis) should not be mistaken as squatters or encroachments on public lands. Since the inception, they had been an integral part of the legitimate housing stock of the city and thus have definite legal and socio-economic connotation (Moitra, 1991). ${ }^{23}$ By the turn of the $20^{\text {th }}$ century itself, these slums of the city had almost reached its saturation point. Over the years, these

\footnotetext{
${ }^{23}$ In 1949, the city passed the first Calcutta Thika Tenancy Act. This legislation was supposed to prevent landowners from evicting tenants unnecessarily. Slum Area (Improvement and Clearance) Act of 1956 prevented further proliferation of these types of bastis. The Calcutta Slum Clearance Bill of 1957 proposed offering subsidized flats to evictees. Vide the Thika Tenancy Act (1981) of the Government of West Bengal, protecting the residents from eviction. The residents pay land tax and can sublet rooms out. These settlements were taken over by the CMC in 1980 and let out directly to tenants.
} 
industries have gone through ups and downs but majority of those old slums still exist and many more new ones have come up. Many of the old slums (i.e. Bastis) ${ }^{24}$ are now over saturated (because of natural growth of population there), and there is a spill over from these ones to newer ones in the southern part of Kolkata (Schenk, 2010, pp. 102-04).

\section{Slums in the Post-Colonial phase:}

The fortune of Calcutta changed dramatically from the early $20^{\text {th }}$ century - first in 1921 with the shift of capital, and again with Partition in 1947. Once thriving industries started to stagnate or decline in this phase. This impacted the rural-urban migration in the city, although it continued but at a slower pace. However, there was incidence of migration through rural-urban linkages that was stimulated by the agricultural and unemployment issues in the villages and by the riots in Bihar and Uttar Pradesh in the 1940s (Schenk 2010). But the Partition of the country posed an enormous challenge to the city that observed a huge influx of refugee migrants from East Pakistan.

There were two major waves of inward-migration that can be noticed since the second half of the twentieth century - first, during 1950s (at the time of India's independence) and second, during 1970s (Bangladesh liberation war). The refugees initially squatted around railway stations and then in many cases flooded vacant lands on the outskirts of the city (mainly in northern and southern parts). In some cases, the refugees (who came during 1950s) were given plots in lease for 99 years by the government at small amount of fees and that created Refugee Resettlement (locally called $u d b a s t u$ ) Colonies. But many of the refugees kept squatting for long. On the other hand, rural migrants slowly developed squatter settlements through evolving rural-urban linkages (Schenk, 2010). These squatter settlements were mainly unauthorised. Among the unauthorised slum types there were encroachments on the roadside or any vacant place (called jhupri), or along the sides of canals (called khaldhar jhupri) by the poor people either displaced from the city itself or due to an excessive increase family size or retrenched from their work place (Kundu, 2003).

During our survey, we have noticed that there are important clusterisations of slums in terms of ethnicity. The slums in northern and central part of Kolkata are mostly inhabited by the migrated population from Bihar, Jharkhand and Uttar Pradesh. The same trend was noticed around the port area, which is the south-western part of the city. The southern and the south-eastern parts of Kolkata slums have relatively high concentrations of Bengali-speaking population of the neighbouring districts (majorly from North \& South 24 Parganas) of Bengal and refugees from Bangladesh (post 1971). However, Bangladeshi refugee settlements - only some of them are legally recognised - are

\footnotetext{
${ }^{24}$ Among the areas where large, old bastis are concentrated are Metiabruz, Rajabazar, Narkeldanga, Sealdah, Beckbagan and Tiljala-Topsia-Tangra. See, Ramaswamy (2008).
} 
scattered all over Kolkata and its adjoining areas. Many of these settlements have become slums over the years.

\section{Mumbai}

\section{Colonial Phase: Birth of slums}

The Mumbai City was founded in the late $17^{\text {th }}$ century, when the Portuguese king ceded all the islands of Bombay to the British ruler. Transfer of power from the Portuguese to the British was completed when the East India Company took possession of Colaba (the southern tip of Salsatte Island) and Old Man's Island around 1664. The city was developed around a newly constructed fort (Fort George) in the main island, from erstwhile Dongri Fort and to the north of the port. As the city started growing gradually within the island, the natives (Koli fishermen) were displaced for the development of the harbour and the port and new migrants entered. The-then Governor, Gerald Aungier, tried to set up business in Bombay by attracting traders, skilled workers and artisans through various inducements. In response to that many traders and artisans from Gujarat came to the newly developing town. This resulted in the first population boom in Bombay - between 1661 and 1675 there was a six-fold increase in population. Many of the prosperous traders were allowed to build houses inside the British fort. The rest - the lesser mortals, who were engaged in handicraft making ${ }^{25}$ and petty trading ghettoed in to form a crowded "native-town" around the walls of the fort. This native town probably gave rise to the first slums in Bombay.

\section{Proliferation of Slums in the Colonial Phase, birth of Dharavi and beyond:}

Till the late eighteenth century, it was primarily a marine supply point, which, unlike Calcutta and Madras, had few links to the hinterland except Gujarat. During the 19th century, Bombay city observed a spurt of slum population that was contemporaneous to large-scale industrialisation and urbanization. During the early nineteenth century, Bombay's growth resulted from military and economic factors including the development of foreign shipping services. Since the middle of $19^{\text {th }}$ century, the fortune of the city changed with the Cotton Boom that was associated with the establishment of railways. The onward growth of Bombay from the second half of the nineteenth century was linked to trade. Many of today's slums are the by-products of the cotton boom. ${ }^{26}$ The rapid growth of mills and shipping, following the cotton boom, was sustained by a large migration

\footnotetext{
${ }^{25}$ The handicraft industries that existed were potteries, hand weaving of both silk and cotton, manufacturing of copper and brass vessels and gold jewelry.

${ }^{26}$ Till the middle of $19^{\text {th }}$ century, India used to export raw cotton to Britain, and import finished textile from there. Once the establishment of railways connected the cotton growing areas of the hinterland to Mumbai city after 1950s, this facilitated faster and supply of cotton to the factories in Britain. But, interestingly this also paved the way for domestic textile production in Mumbai using the existing channel of raw cotton supply and cheap labourers from these hinterlands; this led to establishment of several cotton textile spinning mills in Mumbai around that time - the so called Cotton Boom. Initially the mills started to come around the main city and then spread up to Parel and then expanded westwards all the way to Worli.
} 
from the rest of the Mumbai Presidency (mainly Marathi speaking workers) into a city ill-equipped to deal with them. These workers were initially accommodated in hostels (chawls, ${ }^{27}$ in local language). Most often, the male member of the family would work in Bombay, leaving the rest of the family in the village. Numerous such labour settlements grew around these mills and other places of employment. Eventually, these chawls became tenements, with family members cramming into single rooms, consequently densities increased phenomenally and structures began to deteriorate very fast.

During the late $19^{\text {th }}$ century, the city started to grow towards north further and further. The everexpanding city engulfed many neighbouring villages (e.g. Dharavi, Byculla, Khar) that had their own traditional industries and turned them into slums. In 1880s, concerned with epidemics, the British colonial government expelled several polluting industries and their workers (many Indian residents of the Native Town) to the village of Koliwadas at the distant northern edge of the city and the wellknown slum of Dharavi was born in 1887. The colonial government granted them a 99-year land-lease in 1895 . Among the early settlers in Dharavi, many were involved in producing leather products. This was typically a profession of lowest Hindu castes and of Muslims. Other early settlers included the Kumbhars, a large Gujarati community of potters (another polluting industry). Next was a wave of rural migrants from other states who also poured into the Dharavi region: other artisans from Uttar Pradesh (e.g. the embroidery workers who started the ready-made garments trade) and a large influx of Tamil migrants came in the 1920s. The existing industries created jobs, more labourers moved in, and its population soared past 1 million. However, there was no effort to plan or invest in any infrastructure in or near Dharavi. The living quarters and small-scale factories grew haphazardly, without provision for sanitation, drains, safe drinking water, roads or other basic services (Sharma, 2000, pp. 6-8).

\section{Since the turn of $20^{\text {th }}$ Century:}

Towards the early part of the twentieth century, with the inception of Indian Railways, several mechanical workshops, foundries and other engineering firms were established. Towards the end of first quarter of $20^{\text {th }}$ century, the cotton boom came to a halt as the recession of the $1920 \mathrm{~s}$ set in. After World War II, under strong competition from Japan, the mills started to decline further. But the employment opportunities kept arising contemporaneously in other industries especially manufacturing. The Second World War introduced a number of incentive schemes for industrial expansion. As a result, the manufacturing sector became more diversified: several chemical industries, oil, petrochemical, paper, printing, flour mills and food manufacturing industries came into

\footnotetext{
27 Chawls were rental tenements (mostly on Pagri) constructed in Mumbai by factory owners and landowners for lowincome workers between 1920 and 1956. Later, the Port Authorities and a few other public sector units began renting out similar tenements to their workers. One-room tenements with cooking places and shared common lavatories were provided, with the aim of housing mostly single men for nominal rents.
} 
existence. Construction of docks at the Bombay port helped. The number of industries in Mumbai almost doubled from about 4,000 in 1961 to almost 7800 in 1981, (worth noting that this is the same phase when the fortune of Calcutta was on the wane). With this industrial growth, job opportunities remained buoyant and that attracted more migrants and contributed to the rapid growth of Bombay. During this two decade, there was a massive growth of industrial workers, from 500,000 to over 600,000 . From that point, however, the number of industries remained roughly stable, and the number of industrial workers declined to just over 450,000. Despite the continued dominance of textiles and engineering, Bombay's industrial base is currently quite diversified with a substantial base of printing, petrochemical and consumer goods industries and that still attracts migrants from all over the country and consequently the numbers of slums and their population have increased a great deal.

Housing options for the poor in Mumbai are Chawls, Patra chawls (consisting mainly of semipermanent structures, which can be both authorised and unauthorised), Zopadpattis (squatter housing), Slum Rehabilitation Authority (SRA) Buildings, and pavement dwellings. Although pavement dwellings and chawls have poor slum-like conditions, these do not fall under the legal definition of 'slum'. From the legal authorization perspective, the slums of Mumbai are of three types - Protected (authorized), Declared/Notified (authorized) and unauthorized. Certain slums were declared authorized by the Maharashtra Slum Areas (Improvement, Clearance and Redevelopment) Act, 1971 and protected from eviction. The Notified slums are declared as slums by the Government or Municipal Authority and they deserve the basic minimum requirements of shelter. Slum Rehabilitation Act, 1995 was passed by the Government of Maharashtra to protect the rights of slum dwellers and promote the development of slum areas. The Act aimed to protect anyone from eviction, who could produce a document on city-residency status before January 1995, regardless if s/he lived on the slums. According to BMC data of $2001,53.68 \%$ of the total slums are located on government lands of which $42 \%$ are declared protected and $17 \%$ are notified; whereas of the $43.32 \%$ of slums that are located on private lands, only $14 \%$ are protected and $54 \%$ are notified as slums by the authorities. Thus, about $63 \%$ of the total slums dwellers are somehow protected from eviction threats.

\section{Delhi}

Till the early 1960s 'slums' and 'squatters' in Delhi were mainly concentrated in and around the old city of Delhi (also known as Purani Dilli/Shahjahanabad/Walled City). According to the first socioeconomic survey of slums in Delhi in 1957, there were 1726 slums as "katras" (a form of slum tenements, in a very dilapidated and congested housing) that were largely localised in the Walled City area and there were 61 squatters, called 'basti' or 'jhuggi', around the Walled city and its extensions (in Karol Bagh, Sadar Bazar) and also in New Delhi area (Basu 1988, pp. 106-143). The area of Shahjahanabad has a long history of human settlement and it is well documented but the literature is 
rather silent on the creation and proliferation of squatters (called Jhuggi-Jhopri Clusters, JJC) in Delhi since 1950s. There are two critical phases in the growth of slums in Delhi - (i) restructuring of Colonial Shahjahanabad by the British ruler, which saw the start of the process of slummification, and (ii) post-colonial/independence era which accentuated the process-

\section{Pre-colonial Shahjahanabad: The Grand Old City and its habitants}

Mughal emperor Shahjahan decided to build his capital city in a location known as Firuzabad (named after Firuzshah Tughlaq, which has been inhabited since $14^{\text {th }}$ century) during $17^{\text {th }}$ century (MitraChenoy, 1998). The capital city was developed (for about 60,000 people) around several nodes: the Red Fort and the palace inside it, were in the heart of the city, that was surrounded by the Havelis of Nobles of Emperor, and this inner core (protected with a Wall) was further surrounded by numerous markets (bazars) and fringe settlements (katras) of lesser nobles - traders, craftsmen, servants and labourers. These small scale traders and merchants from various neighbouring regions formed a floating population outside the city wall. The servants and craftsmen were also generally not allowed to settle within city walls, however they formed permanent habitats just outside. Over the years, several new pockets of settlements grew in the suburbs away from the city walls as many nobles moved out - Hindus concentrated in Siddhipura, Sufis settled in Nizamuddin, Muslims in Id Gah and Qadam Sharif, farming community lived alongside the canal that carried water inside the city. The city preserved its character for over 200 years but underwent drastic changes in nature and in community profile when the British ruler occupied the city first in 1820 and again in 1857 with aftermath of Sepoy Mutiny. ${ }^{28}$

\section{Colonial Shahjanabad: Birth of Slums}

Two phases mark this colonial period of Shahjahanabad - before and after 1857. Early British rule was marked by mild activities, they restored and restructured the city and established satellite settlements outside the city walls (Civil Lines, Mubarakbagh, Kishanganj, Cantonment). After 1820, middle class population encroached into the core of the city, which was earlier reserved for elites, British constructed many middle class houses around Jama Musjid area. After the revolt in 1857, with end of Mughal Rule, British restructured large parts of the city, built railway system in 1867 through the walled city by removing gardens and katras in that area, established a temporary capital as Civil Lines and planned a new capital. The notable changes were ejecting the city's population and destroying one third of traditional neighbourhoods. Original settlers of the city, Muslim habitats, were forced out of the area and the abandoned Havelis were sold out to many wealthy Hindu traders. The poorer and middle class community (particularly craftsmen) who used to live in the outskirts moved

\footnotetext{
${ }^{28}$ The Sepoy mutiny refers to the mutiny of Indian troops against the rule of the East India Company.
} 
in and occupied abandoned houses. Larger Havelis were divided among the new heterogeneous settlers from different class, religion and professions. ${ }^{29}$ Besides this, during the construction of the new capital city ("New Delhi"), there was a huge influx of population into the Old City, many of them were either evicted from New Delhi area or migrant labourers employed in the construction of New Delhi. It resulted in a rapid increase in the population of an already crowded Old City between 1916 and 1926 (an estimated 28 per cent addition to the erstwhile population) (Priya, 1993). Nothing was done either for relieving the previous congestion or for housing the new entrants. The settlement pattern once based on class in the Mughal era, started to convert itself to a commerce-hub, numerous household enterprises employ many of the slum resident-labourers, in the early $20^{\text {th }}$ Century.

\section{Post-Colonial Shahjanabad:}

Soon after 'partition' many Muslim families from the area abandoning their houses migrated to Pakistan, and the many Hindu refugees from Pakistan, who got temporary shelter in Purana Qila and Daryaganj, eventually occupied the abandoned houses. These havelis then started functioning as commercial complexes with people running their shops in them. Old Delhi that had been a picture of both change and continuity; it's now a commercial slum. The negligence of the planners towards Old Delhi resulted in its transformation to a large slum area through deterioration and dilapidation. By the Slum Areas (Improvement and Clearance) Act of 1956, government declared it, along with Nizamuddin area, as "slum designated area". Through a notification on 28 April 1994 by Slum \& JJ Department of Government of Delhi about 100,000 Katras/properties have been identified as Slum in the Walled City and its extension. ${ }^{30}$ Last de-notification by Slum \& JJ Department was done in 2004. Some parts of Paharganj were de-notified.

\section{Squatters (around Shahjahanabad) till 1950:}

There were mainly two reasons for the growth of squatters in Delhi especially around the old city. First, British town planners did little towards the systematic extension of the city that could contain ever increasing 'natives' in the old city. There were incidences of spill overs of population from Walled City area into neighbouring Paharganj region and other suburbs in the form of squatters. Secondly, as no provision of housing was premeditated for the large number of skilled and unskilled workers that in-migrated for the construction work of New Delhi, they started squatting in various parts of Delhi. Delhi Improvement Trust (DIT) was set up in 1937 and it functioned till 1950. DIT's development activity in extension areas of the old city and slum clearance activity created more clutter. Priya (1993) notes "DIT had done next to nothing towards increasing housing for the previous

\footnotetext{
${ }^{29}$ Mitra-Chenoy (1998) and Zonal Development Plan, walled City (Part Zone A and C), September 2007

${ }^{30}$ There are two types of properties: private property (97\% of all properties); evacuee property (3\% of all properties), which are under the Slum and JJ Department.
} 
poor inhabitants or for the new immigrants. If anything it had only added to the problem by demolishing some of the housing available to the poor under slum clearance schemes without adequate rehousing so that the evicted added to the congestion of surrounding areas. Squatter settlements, the jhuggi jhopri bastis, started coming up in and around the new extension areas and at the periphery of New Delhi."

\section{Post-Independence growth of squatters:}

In the post-independence era, the population of Delhi increased many folds for two reasons. First, immediately after the independence Delhi registered a deluge of refugee immigrants from West Pakistan. Secondly, the employment opportunities (formal and informal), 'city development' activity and the increasing need for service and labour in the better-off urban sections had led to continuing large-scale migration from rural areas, particularly from the backward state areas due to regional economic imbalances. The result was a rapid increase in jhuggi-jhopris. These jhuggi-jhopri clusters (JJCs) are the second kind of slums in Delhi. But that refugee influx did not create a major problem of squatting in the city as the ministry of rehabilitation did a credible job by rehabilitating them in various part of the city in different colonies. However, similar conviction and effort were either completely missing or plagued by 'anti-poor bias' on the part of the government when it comes towards rehabilitation of poorer, jhuggi-dweller, rural migrants to the city. The squatters kept increasing since 1950s. The JJC is one of seven government-designated categories of unplanned settlements in Delhi. ${ }^{31}$ Incidentally many of the squatter clusters grown in this phase around the vacant places near many resettlement colonies.

\section{The Resettlement (and Relocation) Colonies:}

Slum clearance work was taken up in a big way since 1960. In the first phase, between 1960 and 1977, 45 resettlement colonies were created in the periphery of the city by clearing various squatter settlements within the heart of the city. The purpose was to secure speedy and expeditious implementation of the slum clearance schemes and connected projects. This activity got a momentum specifically during the period of Emergency in 1975-76 - around 27 resettlement colonies were laid out relocating 120 thousands squatter households. However, given the limited size of slum population prior to 1970, it was possible to shift most of the squatting households to various resettlement colonies, but after 1970, as the rate of migration increased, resettlement has not been able to keep pace with the growth of JJ clusters. The squatter resettlement colonies were site-cum-services schemes. In the initial phase each squatter family was provided a plot of 80 square yards long-term

\footnotetext{
${ }^{31}$ Categories of settlements in Delhi presented in Economic Survey of Delhi, 2008-2009, page 169, citing Delhi Urban Environment and Infrastructure Improvement Project (DUEIIP)-2021.
} 
tenure, however later the plot size was only of 25 square yards. The squatter-resettlement colonies were developed with metalled roads, public parks, water supply, public lavatories, street lighting, drains, shops, schools, dispensaries and community centres. Small-scale industrial units (e.g. Okhla, Mayapuri, Rohini-Bawana Industrial areas) were created and located close to these colonies to ensure employment in the neighbourhood. The attempt was to make an all-round development for the relocated 'squatters' and that is why it was 'resettlement' and not just 'rehousing'. But the present day ground reality pose a different picture that can only invoke pity. Dupont (2008, pp. 80) underlines the relevant features of the Delhi JJ resettlement scheme, which does not involve proper rehousing but a simple relocation on developed plots in resettlement colonies. In a recent move, vide an $\operatorname{order}^{32}$ of June 2013, the Government of NCT of Delhi conferred the freehold ownership rights to the occupiers (upto $31^{\text {st }}$ March 2007).

Another drive of rehabilitation started in the middle of 1990s and went till 2007. In this phase 16 new colonies were created either in more far-flung periphery of the city or by the side of existing resettlement colonies that are called Relocation Colonies. Of the $217 \mathrm{JJ}$ clusters/sub-dusters demolished from 1990 to 2007 (Dupont 2008, pp. 85), majority of the 65 thousands squatter households that were relocated were given plots of size 25 yards, and others were allotted small oneroom flats, both without any sanitation facility. These resettlement and relocation colonies at present estimated to include nearly 420,000 households, about 15 per cent of Delhi's population. There are total 47 resettlement colonies spread over 7 revenue districts housing about 1.1 million population and 16 relocation colonies spread over 5 revenue districts housing about 300 thousands population. ${ }^{33}$

\section{Demographics Characteristics}

In the previous section, we have discussed how differently slums in Kolkata, Mumbai and Delhi have historically evolved over time. Their different paths of evolution have shaped some of the demographic characteristics. Slums in these three cities comprise of heterogeneous groups of population from diverse ethnic, lingual and provincial background, such as people from various districts of native state of each city as well as from various parts of the country (and abroad). Table 1 captures this heterogeneity by geographical origin. This table presents shares of surveyed households according to their provincial origin as well as according to the household heads' migration status whether the household head was born within or migrated to each city.

\footnotetext{
32 The Order was accessed at Delhi Government's website on 19 September 2015: http://delhi.gov.in/wps/wcm/connect/cbe80e00402738b9b36dbba13b643d8e/relocation+of+slum+and+jj+new.pdf?MOD=A JPERES\&lmod=-1999015349\&CACHEID=cbe80e00402738b9b36dbba13b643d8e.

${ }^{33}$ The figure has been calculated on the basis of average household size of five persons, according to census data 2011.
} 
The first noteworthy observation is that majority of the slums dwellers in any city are either from the native state (except Delhi) or originally from North-Central region of India. An overwhelming 74\% of households in Delhi's JJ clusters are from the North-Central region, which may be due to Delhi's close proximity to the states in this region. It should be noted that the state of UP shares the largest boundary with Delhi. Although Mumbai is far from this region, owing to the job opportunity it creates, still manages to attract migrants. Kolkata and Mumbai, in addition, attract a large share of dwellers from adjoining districts of their native states as well as from neighbouring states. Heads of a third of the slum households in Kolkata and a 45\% of slum households in Mumbai have reported their state of origin as the native state. Notice that Kolkata and Delhi slums are also home to a significant fraction of migrant-heads ( $8.7 \%$ and $5.1 \%$, respectively) who trace their root back to places outside of India. ${ }^{34}$ For example, Kolkata bears the brunt of partition during independence and again during the liberation of Bangladesh, where a significant number of migrants took refuge from Bangladesh (erstwhile East Pakistan). Delhi slums are, on the other hand, home to foreign migrants mainly from Pakistan. These findings confirm our discussion in the historical genesis part.

Table 1: Migration Status of Household Heads by the Region of Origin

\begin{tabular}{|c|c|c|c|c|c|c|c|c|c|c|}
\hline \multirow{2}{*}{ Regions of Origin* } & \multicolumn{2}{|c|}{ Kolkata } & \multicolumn{2}{|c|}{ Mumbai } & \multicolumn{2}{|c|}{ Delhi } & \multicolumn{2}{|c|}{ Delhi JJ } & \multicolumn{2}{|c|}{ Delhi RR } \\
\hline & Migrate & Born & Migrate & Born & Migrate & Born & Migrate & Born & Migrate & Born \\
\hline Native State & 12.1 & 20.9 & 22.4 & 22.4 & 0.0 & 2.6 & 0.0 & 2.3 & 0.0 & 2.9 \\
\hline North-Central India & 20.3 & 35.7 & 20.8 & 6.8 & 55.8 & 12.2 & 65.0 & 8.8 & 44.3 & 16.4 \\
\hline North-West India & 0.5 & 0.1 & 2.4 & 1.0 & 9.8 & 8.8 & 8.2 & 3.7 & 11.8 & 15.0 \\
\hline Central India & - & - & 0.4 & 0.1 & 3.6 & 0.3 & 4.4 & 0.3 & 2.6 & 0.3 \\
\hline Eastern India & 0.5 & 0.4 & 1.4 & 0.0 & 1.2 & 0.0 & 1.9 & 0.0 & 0.4 & 0.0 \\
\hline Western India & 0.0 & 0.1 & 4.3 & 4.5 & 1.0 & 0.3 & 1.8 & 0.5 & - & - \\
\hline Southern India & 0.0 & 0.7 & 7.5 & 5.9 & 1.1 & 1.0 & 1.1 & 0.8 & 1.2 & 1.3 \\
\hline Out of India & 4.0 & 4.7 & 0.2 & 0.2 & 0.8 & 1.6 & 1.1 & 0.2 & 0.5 & 3.3 \\
\hline Total & 37.3 & 62.7 & 59.2 & 40.8 & 73.3 & 26.7 & 83.3 & 16.7 & 60.8 & 39.2 \\
\hline Average Age of Head & 51.3 & 49.2 & 50.3 & 46.6 & 49.1 & 44.3 & 46.7 & 41.8 & 53.1 & 45.7 \\
\hline
\end{tabular}

"Note: Figures (except the last row) represent row wise percentage share between the two columns for each city. The native state of Kolkata is West Bengal, the native state of Mumbai is Maharashtra and that of Delhi is Delhi itself. North-Central region consists of Uttar Pradesh, Bihar, Jharkhand and Uttarakhand; North-West region consists of Rajasthan, Haryana, Punjab, Himachal Pradesh, Jammu and Kashmir and Delhi; Central region includes Madhya Pradesh, Chhattisgarh; Western region includes Maharashtra, Gujarat, Goa, and Daman-Diu; Southern region consists of Tamil Nadu, Kerala, Karnataka, Andhra and Telengana; Eastern region includes West Bengal and Orissa. Regions other than the native state for the corresponding city do not include the native state.

The second noteworthy observation from Table 1, which links with the historical genesis of the slums of cities, is that only around a quarter of the heads in Delhi slums and two-fifth of the heads in Mumbai slums were born within respective cities. In Kolkata, on the other hand, more than three-fifth of the heads were born within the city.

\footnotetext{
34 The figures of foreign migrants are somewhat understated, as the foreign migrants do not systematically reveal this
} information during interviews. 
This second observation made in the previous paragraph is strengthened in Figure 1, where we present the decadal migration pattern in the past 100 years of all surveyed households (irrespective of whether the head of the household was born or migrated). The households were asked: when did the household moved to the city including its previous generation? Again, supporting the historical genesis, it is evident both from Figure 1 that Kolkata has witnessed a larger pre-independence migration, whereas Mumbai and Delhi has witnessed relatively larger post-independence migration. Let us have a look at the relative speed of in-migration of labourers, and the process of slummification (both are closely linked to the industrialisation process), that is reflected in this graph. The trough in-flows of migrant workers during 1920-30 for all cities reflect the low ebb in the industrialisation process aftermath World War I. The in-migration of labourers and the process of slummification for Kolkata primed roughly during 1940-60 and since then it has been on the decline. The same for Mumbai reached a peak roughly during 1970-80 and Delhi observed the major spurt of labour in-migration roughly during 1980s, which incidentally coincided with the phase of break in the slum eviction and rehabilitation process. ${ }^{35}$

\section{Figure 1: Decadal Migration Pattern of the Surveyed Households in Three Cities}

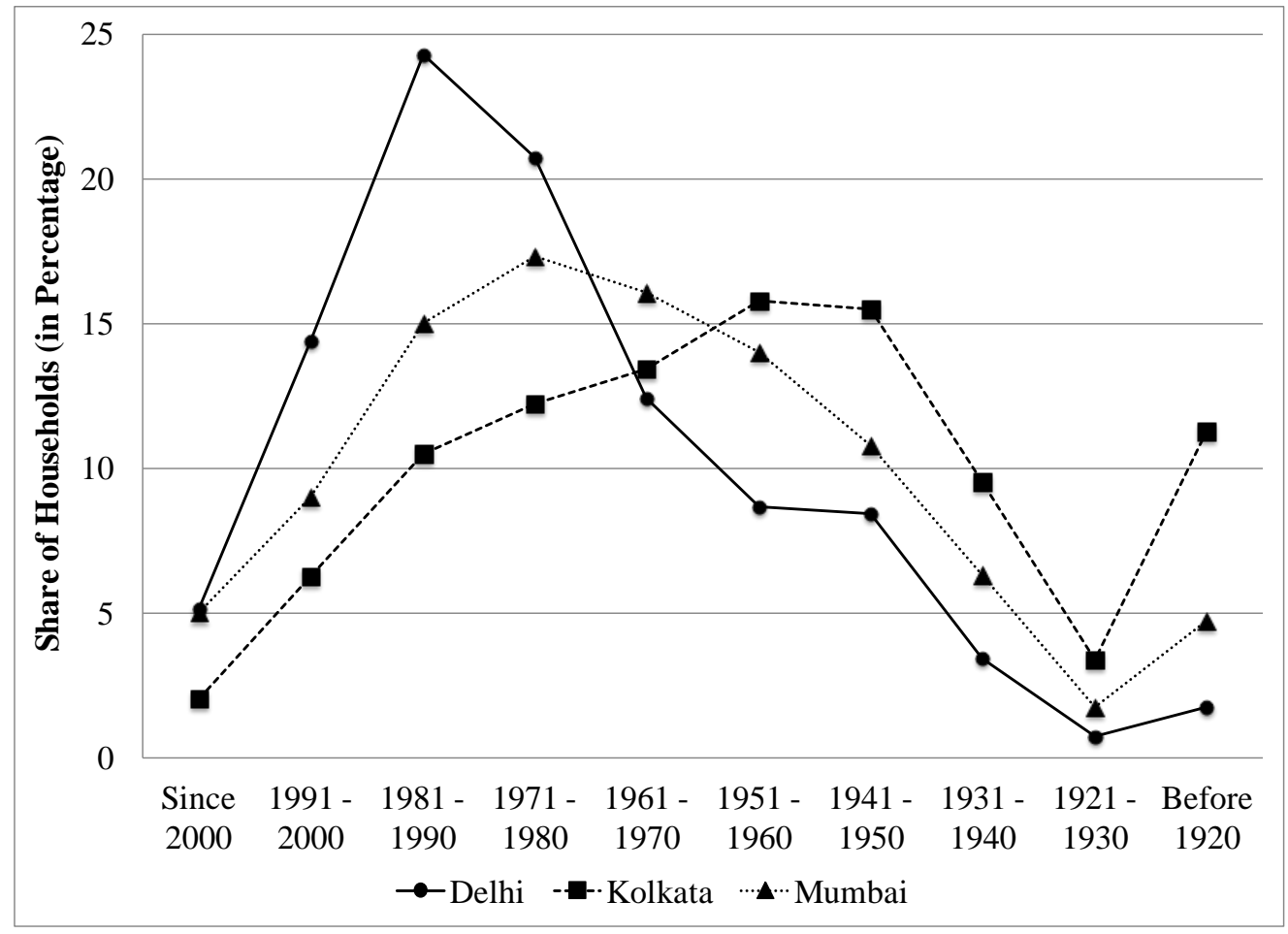

In Table 2, we present the migration pattern of only those households, whose present heads have migrated across different decades (note that this is only a subset of all the households that migrated

\footnotetext{
${ }^{35}$ Please note that the percentage of recently migrant households that settled in these cities may be underestimated by the fact that many of them find spaces to live in footpaths.
} 
and exclude those heads who were born in respective cities). Consistently, the share of migration has slowed down at the dawn of the new millennium in all cities. The majority of the migration took place between 1970 and 2000. Of the migrated households, $65-80 \%$ household heads migrated to the slums of cities in this period of 30 years.

Table 2: Decadal Distribution of Migrated-Heads in Slums of Three Cities

\begin{tabular}{lcccc}
\hline & Kolkata & Mumbai & Delhi JJ & Delhi RR \\
\hline After 2000 & $6.2 \%$ & $9.4 \%$ & $10.3 \%$ & $4.3 \%$ \\
$1991-2000$ & $17.3 \%$ & $17.3 \%$ & $23.4 \%$ & $13.8 \%$ \\
$1981-1990$ & $22.1 \%$ & $27.8 \%$ & $37.7 \%$ & $29.9 \%$ \\
$1971-1980$ & $25.0 \%$ & $24.0 \%$ & $21.0 \%$ & $29.9 \%$ \\
$1961-1970$ & $11.3 \%$ & $12.7 \%$ & $4.7 \%$ & $15.5 \%$ \\
1960 or Before & $18.1 \%$ & $8.9 \%$ & $2.9 \%$ & $6.7 \%$ \\
\hline
\end{tabular}

In Table 3, we present additional demographic characteristics, such as the distribution of households by religion and caste, household size, household head's gender, sex ratio and educational performance among adults and children. In our survey, more than $90 \%$ household heads have identified themselves as either Hindu or Muslim and so people from other religions are in minority in slums. However, the composition between the two dominant religious communities varies across cities. The share of Muslim households is highest in Kolkata (31.5\%) and lowest in Delhi's RR colonies (9.1\%). It is noteworthy that majority of the Muslim population in slums are from Bihar and Uttar Pradesh. The caste composition of slum households is also quite different across cities. In Delhi's JJ clusters and RR colonies, over half of the households identify themselves as scheduled castes. The share of scheduled caste in other two cities is in the range of $20-25 \%$. The shares of households identifying themselves as other backward classes in slums of Delhi and Mumbai stand at 20-24\%, but the corresponding share is quite low in Kolkata. ${ }^{36}$

The average household size of the surveyed households appears to be lower in slums of Mumbai and Kolkata. Around 2/3 of the households in Delhi's JJ clusters and RR colonies have more than 5 or more members, whereas the corresponding incidences in Kolkata and Mumbai are only around half. The average household size may be affected by the number of children in the household. In Kolkata and Mumbai slums, 37.9\% and 44\% households, respectively, do not have any child and only 12\% households in each of these two cities have three or more children. In Delhi, however, smaller fraction of households has no children and much higher fraction of households has three or more children.

\footnotetext{
${ }^{36}$ We have noted during our interviews that many households belonging to non-general caste categories preferred to represent themselves belonging to the general caste either because they were not able to get respective caste certificates from their place of origin or because they found it embarrassing to reveal the caste.
} 
Table 3: Demographic Features: Religion, Caste and Household Characteristics

\begin{tabular}{|c|c|c|c|c|}
\hline & Kolkata & Mumbai & Delhi JJ & Delhi RR \\
\hline \multicolumn{5}{|l|}{ I. Household Head's Religion } \\
\hline Hindu & $65.7 \%$ & $69.1 \%$ & $83.5 \%$ & $88.8 \%$ \\
\hline Muslim & $31.5 \%$ & $21.9 \%$ & $15.4 \%$ & $9.1 \%$ \\
\hline Christian & $2.5 \%$ & $2.4 \%$ & $0.5 \%$ & $0.3 \%$ \\
\hline Sikh & $0.0 \%$ & $0.1 \%$ & $0.4 \%$ & $1.4 \%$ \\
\hline Other & $0.2 \%$ & $6.5 \%$ & $0.2 \%$ & $0.4 \%$ \\
\hline \multicolumn{5}{|l|}{ II. Household Head's Caste } \\
\hline Scheduled caste $(\mathrm{SC})$ & $25.7 \%$ & $20.2 \%$ & $53.4 \%$ & $50.4 \%$ \\
\hline Scheduled tribe (ST) & $0.5 \%$ & $1.6 \%$ & $2.4 \%$ & $0.2 \%$ \\
\hline Other backward class (OBC) & $9.4 \%$ & $23.9 \%$ & $22.2 \%$ & $19.8 \%$ \\
\hline General + Undisclosed & $64.5 \%$ & $54.4 \%$ & $22.0 \%$ & $29.7 \%$ \\
\hline \multicolumn{5}{|l|}{ III. Household Size } \\
\hline Average household size & 5.1 & 4.9 & 5.5 & 5.4 \\
\hline One member household & $2.1 \%$ & $2.7 \%$ & $2.2 \%$ & $0.6 \%$ \\
\hline 2-4 members household & $46.3 \%$ & $44.9 \%$ & $31.5 \%$ & $33.2 \%$ \\
\hline 5 or more members household & $51.6 \%$ & $52.4 \%$ & $66.3 \%$ & $66.1 \%$ \\
\hline \multicolumn{5}{|l|}{ IV. Number of Children in Households } \\
\hline No children & $37.9 \%$ & $44.0 \%$ & $28.4 \%$ & $33.8 \%$ \\
\hline One/two children & $26.7 \%$ & $23.0 \%$ & $21.6 \%$ & $22.8 \%$ \\
\hline Three or more children & $12.0 \%$ & $12.3 \%$ & $27.2 \%$ & $18.7 \%$ \\
\hline V. Household Head's Gender (Female) & $19.7 \%$ & $18.8 \%$ & $13.8 \%$ & $17.7 \%$ \\
\hline \multicolumn{5}{|l|}{ VI. Sex ratio (females per 1,000 males) } \\
\hline Overall & 945 & 951 & 888 & 935 \\
\hline Among children (14 years or less) & 899 & 880 & 860 & 840 \\
\hline Among adults ( 15 years or more) & 959 & 971 & 900 & 968 \\
\hline \multicolumn{5}{|l|}{ VII. Adult Education (15 Years and More) } \\
\hline Percentage literate & $82.0 \%$ & $89.6 \%$ & $70.1 \%$ & $83.7 \%$ \\
\hline Average years of schooling completed & 6.6 & 8.7 & 6.4 & 8.0 \\
\hline \multicolumn{5}{|l|}{ VIII. School/College Enrolment Rate } \\
\hline Among 6-14 years & $93.8 \%$ & $97.3 \%$ & $93.6 \%$ & $97.0 \%$ \\
\hline Among $15-18$ years & $74.8 \%$ & $85.3 \%$ & $68.6 \%$ & $79.2 \%$ \\
\hline Among 19-21 years & $36.4 \%$ & $54.0 \%$ & $38.9 \%$ & $55.1 \%$ \\
\hline
\end{tabular}

In order to capture the demographic difference across gender, we look at the share of households where the heads are females as well as the sex ratios within slums. We observe that the less than onefifth of the households in slums of all cities are headed by females. The sex ratio, which is the number of females per 1,000 males, reveals an interesting pattern. According to the Census Authority of India, the overall sex ratio in slums has improved from 887 in 2001 to 928 in 2011. In our surveys, we find that slums in Kolkata, Mumbai and Delhi's RR colonies have similar or slightly better overall sex ratios (935 in Delhi RR, 951 in Mumbai and 945 in Kolkata). However, the sex ratio in Delhi's JJ colonies is much lower at 888 . Decomposing the overall sex ratio across two age groups -14 years or less and 15 years or more, we find that the sex ratio is consistently lower among the younger groups. In Delhi's RR colonies, the sex ratio among the younger age group is only 840 . This is a very disturbing trend and requires in-depth research by demographers. A report by ASHA (2011) notes that the child sex imbalance (in case of Delhi) is largely driven by sex-selective abortions, in turn 
influenced by discrimination against females in education and opportunity, along with the burden of dowry payments at marriage.

In the final parts of Table 3, we present adult literacy rates, the average years of schooling completed by adults and child enrolment rates. According to census 2011, the literacy rate is $84.5 \%$ in urban slums. We however find differences in literacy rates across cities, where the adult literacy rate is lowest (70.1\%) in Delhi's JJ clusters, and highest in slums of Mumbai (89.9\%). The average years of schooling follows similar pattern across cities. The highest average years of schooling is observed in Mumbai, and the lowest in Delhi's JJ clusters. Note that the average years of schooling among adult slum dwellers in no city surpass 9 years.

In India, the statutory age requirement for admission to the first grade in most states is above 5 (or 6 ) years. Therefore, a child should normally complete their primary education (i.e. the fifth grade) at age 11, upper primary education (i.e. the eighth grade) at age 14, secondary education (i.e. the tenth grade) at age 16 and higher secondary education (i.e., the twelfth grade) at age 18 . We calculate child school attendance rate (SAR, hereafter) as percentage of children attending school within each age category. Overall, the child-SARs among 6-14 age groups are more than 90\% in slums of all cities. While the picture is quite heartening, still 3-7\% children are out of school in that age group. In general, attendance rates gradually fall in successive age brackets. SARs drop quietly sharply beyond age 14 (i.e. beyond the eighth grade) in slums of all cities. The drops are quite drastic (20-26\%) in Delhi's JJC and Kolkata; whereas in Mumbai and Delhi's RR colonies, the drops are around 15\%.

\section{Material Well-being}

In this section, we now compare the material well-being in slums across cities, where we specifically look at a number of housing characteristics (Table 4), access to crucial housing facilities (Table 5) and possession of major assets (Table 6).

\section{Housing:}

In Table 4, we present certain household characteristics. Among household characteristics, we first look at the household tenancy type, which differs across cities. Possession of houses is mainly divided into two categories - owned houses and rented tenancy. Historically, tenancy is of three types thika/pagri (long term lease with nominal monthly rent but with initial down payment), informal tenancy (mostly oral and unspecified tenure) and any other form (e.g. short lease rented, rented shared and others). Thika tenancy is more prevalent in Kolkata bastis, whereas pagri system is more common in Mumbai Chawls and older bastis. In Delhi, more than $80 \%$ of constructions are owned by the households; whereas only $12-15 \%$ of the constructions are rented. However, owning a house not 
necessarily transpired into a legally secured tenure if the houses are built on encroached upon public land or even on lands that are owned by private entities (but not necessarily by the slum dwellers themselves) (e.g. squatter JJ clusters in Delhi). In Mumbai also $73 \%$ of constructions are owned (many of these are in unprotected slums i.e. on encroached land) and 27\% are rented. In Kolkata, however, only $37.9 \%$ of constructions are owned and as many as $62 \%$ of constructions are rented of which 37.5\% are rented through thika or pagri tenancy. Many Pagri tenants in Mumbai also claimed to be the owner of the houses.

Table 4: Characteristics of Housing in Slums of Three Cities

\begin{tabular}{|c|c|c|c|c|}
\hline & $\begin{array}{l}\text { Kolkata } \\
(\%)(\mathrm{SE})\end{array}$ & $\begin{array}{l}\text { Mumbai } \\
(\%) \quad(\mathrm{SE})\end{array}$ & $\begin{array}{l}\text { Delhi JJ } \\
(\%)(\mathrm{SE})\end{array}$ & $\begin{array}{l}\text { Delhi RR } \\
(\%)(\mathrm{SE})\end{array}$ \\
\hline \multicolumn{5}{|l|}{ I. Type of Tenancy } \\
\hline Own house 37 & $37.9(2.16)$ & $73.3(1.29)$ & $87.1 \quad(1.17)$ & $84.3(1.89)$ \\
\hline Rented Tenancy (Thika \& Pagri) & $37.5(2.12)$ & $8.9(0.82)$ & $1.4(0.40)$ & $0.5(0.38)$ \\
\hline Informal tenancy & $16.0(1.74)$ & $7.6(0.78)$ & $8.5(0.97)$ & $12.5(1.70)$ \\
\hline Other form of tenancy & $8.5(1.18)$ & $9.3(0.85)$ & $2.5(0.56)$ & $1.0(0.54)$ \\
\hline \multicolumn{5}{|l|}{ II. Duration of the Construction } \\
\hline 10 years or less & $7.6(1.28)$ & $18.7(1.12)$ & $19.6(1.35)$ & $25.9(2.28)$ \\
\hline More than 10 , but 20 or less years & $11.1(1.51)$ & $14.3(1.00)$ & 32.5 (1.64) & $21.3(2.11)$ \\
\hline More than 20 , but 30 or less years & $7.7(1.21)$ & $17.9(1.11)$ & $32.8(1.63)$ & $17.0(1.84)$ \\
\hline More than 30 , but 50 or less years & $26.0(2.05)$ & $35.3(1.37)$ & $11.0(1.09)$ & $32.2(2.39)$ \\
\hline More than 50 years & $42.9(2.20)$ & $12.9(0.95)$ & $1.1(0.35)$ & $0.5(0.34)$ \\
\hline Don't Know/No Info & $4.7(0.85)$ & $0.9(0.27)$ & $3.0(0.59)$ & $3.1(0.85)$ \\
\hline \multicolumn{5}{|l|}{ III. Type of Constructing } \\
\hline Pucca & $\overline{23.7(1.89)}$ & $48.2(1.42)$ & $15.7(1.24)$ & $83.5(1.95)$ \\
\hline Semi Pucca & $74.5(1.92)$ & $49.7(1.42)$ & 80.1 (1.38) & $14.8(1.87)$ \\
\hline Kutcha & $1.6(0.43)$ & $0.6(0.24)$ & $3.0 \quad(0.59)$ & $0.5 \quad(0.35)$ \\
\hline \multicolumn{5}{|l|}{ IV. Members per Sleeping Room } \\
\hline Less than 3 & $\overline{28.8(1.99)}$ & $28.8(1.33)$ & $27.4(1.56)$ & $38.9(2.49)$ \\
\hline 3 or more but less than 6 & $55.0(2.27)$ & $58.8(1.44)$ & $51.9(1.75)$ & $49.9(2.57)$ \\
\hline 6 or more & $16.0(1.62)$ & $12.3(0.96)$ & $19.5(1.38)$ & $10.0(1.52)$ \\
\hline No house & $0.2(0.08)$ & $-\quad-$ & $1.2(0.37)$ & $1.2(0.55)$ \\
\hline \multicolumn{5}{|l|}{ V. Income Generated from } \\
\hline Housing ownership & $\overline{10.9(1.55)}$ & $7.2(0.75)$ & $6.6 \quad(0.85)$ & $13.8(1.81)$ \\
\hline Land ownership & $4.5(0.90)$ & $7.8(0.78)$ & $6.6(0.86)$ & 12.1 (1.67) \\
\hline Housing/Land ownership & $14.8(1.71)$ & $13.9(1.00)$ & $12.4(1.13)$ & $23.9(2.21)$ \\
\hline
\end{tabular}

The second panel of Table 4 presents the duration of construction of houses, which is related to the settlement and growth of the slums over time. We divide the duration of constructions into five categories: 10 years or less, 10-20 years, 20-30 years, 30-50 years and more than 50 years. This particular characteristic reveals an interesting difference between cities, by capturing where slums are still growing rapidly and where the slums are more or less saturated. In Kolkata, $42.9 \%$ of constructions are more than 50 year old, nearly $69 \%$ of constructions are more than 30 year old and

\footnotetext{
${ }^{37}$ It is worth noting that owning a house in slums by a slum dweller does not certainly mean that the house is built on a legally owned land by that slum dweller. Residents of Delhi RR colonies used to own 99 year long leasehold from the government, which was later converted to freehold. Similarly, SRA building residents (if not on rent) in Mumbai also hold 'deferred freehold' status. Readers are requested to see the relevant discussion in the slum typology section.
} 
only $18.7 \%$ of constructions are 20 year old or less. In Mumbai on the other hand $18.7 \%$ constructions are only 10 year old or less and merely $12.9 \%$ households are more than 50 year old. Quite a different picture is visible in JJ clusters and RR colonies of Delhi, where only $1.1 \%$ and $0.5 \%$ of constructions, respectively, are 50 years or older. Most constructions (nearly 85\%) in JJ clusters are developments not older than 30 years and $19.6 \%$ of the constructions were developed within the past ten years. The earliest resettlement colonies were built between 1960 and 1977, which is evident from the final column of Table 4: nearly 32.2\% of constructions were built between 30 and 50 years. However, newer constructions appear to have been built as well: $17 \%$ constructions are $20-30$ years old, $21.3 \%$ constructions are 10-20 years old and $25.9 \%$ constructions are as new as being built within the last 10 years. The trend is quite consistent with the migration pattern observed in the Table 2 earlier.

The housing characteristic that we consider next is the type of constructions. Slums or squatters are often characterized by poorer quality housing structures compared to the rest of the city. We divide the types of construction in three categories: pucca, semi-pucca, and kutcha. ${ }^{38}$ Looking at this characteristic, we do not find a consistent picture across three cities. Although the proportions of Kutcha constructions are very low in all cities, the distributions of other two types vary from city to city. In Mumbai, nearly half of the constructions are pucca; whereas in Kolkata, only a quarter of all slum constructions are pucca. Given that $69 \%$ of constructions in Kolkata are older than 30 years, this figure seems surprising. However, most of these semi-pucca houses are in the old colonial day's bastis and the dwellers are not the owners, rather they live as tenants - either thika/pagri tenancy or other type of tenancy. Vide the Thika Tenancy Act (1981) of the Government of West Bengal (that seeks to protect the residents from eviction), these settlements were taken over by the Calcutta Municipal Corporation in 1980s and let out directly to tenants; this led to the maintenance of status quo of those semi-pacca houses. Another strikingly contrasting picture is observed within Delhi. In JJ clusters, $83 \%$ of constructions are either semi-pucca or kutcha, but the same proportions of constructions are pucca in RR colonies. Majority of the semi-pucca or kutcha houses of Delhi JJ slums, although owned, are actually built on public lands (railways, local government bodies etc.) and have been subjected to constant threat of eviction and demolition. Further, constructing a pucca structure in these slums draws attention of civic bodies or policemen, which results in graft payments by the dwellers. Due to these problems, majority the dwellers might not have chosen to construct pucca houses. In Delhi RR, on the other hand, in most of the cases plots have been allotted for

\footnotetext{
${ }^{38}$ A house is defined as 'pucca' if the house is built of improved floor, roof and wall materials throughout; a house is defined as 'semi pucca' if the house is partly built of unimproved materials and partly of improved materials; and a house is defined as 'kutcha' if it is built throughout of unimproved floor, wall and roof material. Unimproved floor materials include mud, dung, sand, loose brick, stone slab, bamboo, and raw wood planks; Unimproved wall materials include thatch, palm leaf, grass, wood, mud, bamboo, stone slab, rustic mat, tile, un-burnt brick, loosely packed stones, and tin-shed; and Unimproved roof materials include thatch, palm leaf, wood, mud, bamboo, stone slab, rustic mat, tile, un-burnt brick, cardboard, and tin.
} 
construction of houses. The original allottees or their descendants of these colonies had taken the benefit of this tenure security to construct pucca houses.

Over-crowding:

Although we have found wide difference in the type of constructions across cities, we do not find much difference across the cities while consider the 'crowding' within households, which is measured by members per sleeping room (see, panel IV of Table 4). Unlike in rural areas, the competition for living spaces is more stringent in urban areas and especially in slums. This has already been reflected by the average household size in slums of three cities. However, is this large average household size supported by adequate number of sleeping rooms? This characteristic appears to be quite similar in slums of Kolkata, Mumbai and JJ clusters of Delhi, where less than three members reside per sleeping room in $27-29 \%$ of constructions, three or more but less than six members reside per sleeping room in majority of the constructions (52-59\%), and 6 or more members reside per sleeping room in smallest fraction of constructions (12-19\%). Slums in RR colonies are characteristically similar, but less than three members per room reside in a much larger proportion of constructions (38.9\%). The 2005/06 National Family Health Survey report also found that $48 \%$ of Delhi slum households had at least five, and $20 \%$ had at least seven, family members sleeping in the same room.

In order to explore material well being further, we look at the households' access to various housing facilities, which are reported in Table 5. We especially look at the access to electricity, sanitation facilities, drinking water and places used for cooking. We find that slums in these three cities have good coverage to access to electricity, where $94 \%$ or more households have access to electricity in all cities for 18-24 hours. In Mumbai, the figure is $99 \%$ of households.

\section{Sanitation:}

India is known to have made notoriously slow progress in improving access to sanitation - especially in rural areas, which is also evident from the NFHS 2005/06 report. The problem is also reflected in our study on slums; a report by NCAER survey in Delhi and Chennai slum colonies (2002) also reflects similar pattern. Looking at the type of access to sanitation facilities, we find that only less than $30 \%$ of households have personal facilities in Kolkata, Mumbai and Delhi's JJ clusters. In fact, in Kolkata and JJ clusters of Delhi, only 16-18\% of personal facilities are not shared. In Kolkata, Mumbai and Delhi's JJ clusters, $67-72 \%$ of households appear to use private or publicly available shared facilities. Alarmingly, in Delhi JJ clusters, nearly $10 \%$ of households do not have any sanitation facility. However, NFHS-3 (2005-06) survey found that just 5\% of poor families in Delhi had unshared toilet facilities, and $19 \%$ of slum residents had no toilet facility. As well, less than $60 \%$ of Delhi slum homes had even one window. So over the time (between 2006 and 2014) in terms toilet 
facility, some improvement has taken place in Delhi JJ Clusters. The rate of access is much better in RR colonies of Delhi where nearly $82 \%$ of households have access to non-shared personal facilities; another 5\% has personal but shared toilet facility. Thereby, remaining 13\% households are using either shared public facility or other means. This fact is worrisome, as these $13 \%$ households are living in newly created 'relocated colonies'. Tiny allotted plot size (25 sq.yds. or less) coupled with no provision of good sewerage system do not allow residents to construct their own sanitation facilities and force them to use paid public toilets (e.g. Bawana Relocation Colony, Delhi).

Table 5: Access to Various Housing Facilities in Slums of Three Cities

\begin{tabular}{|c|c|c|c|c|}
\hline & Kolkata & Mumbai & Delhi JJ & Delhi RR \\
\hline & $(\%) \quad(\mathrm{SE})$ & $(\%) \quad(\mathrm{SE})$ & $(\%) \quad(\mathrm{SE})$ & $(\%) \quad(\mathrm{SE})$ \\
\hline I. Access to electricity (18-24hr) & $94.5(0.98)$ & $98.8(0.33)$ & $94.9(0.75)$ & $94.3(1.10)$ \\
\hline \multicolumn{5}{|l|}{ II. Type of access to sanitation facility } \\
\hline 1. Personal Facility & $29.7(1.98)$ & $25.9(1.24)$ & $21.7(1.33)$ & $87.2(1.73)$ \\
\hline 1.1. Facility shared & $13.0(1.47)$ & $0.8(0.26)$ & $3.2(0.58)$ & $5.4(1.18)$ \\
\hline 2. Government/Private Facility & $69.0(2.00)$ & $72.3(1.26)$ & $67.0(1.54)$ & $11.6(1.66)$ \\
\hline 3. Other Facilities & $0.7(0.36)$ & $0.2(0.11)$ & $1.5(0.42)$ & $0.0(0.00)$ \\
\hline 4. No Facility & $0.6(0.31)$ & $1.6(0.35)$ & $9.9(1.04)$ & $1.2(0.55)$ \\
\hline \multicolumn{5}{|l|}{ III. Time to access the sanitation facility } \\
\hline One minute or less & $65.9(2.15)$ & $35.9(1.37)$ & $24.1(1.38)$ & $87.5(1.71)$ \\
\hline Two to Four minutes & $22.5(1.88)$ & $31.6(1.33)$ & $23.6(1.50)$ & $4.1(1.07)$ \\
\hline Five minutes or more & $10.4(1.47)$ & $31.2(1.35)$ & $47.0(1.69)$ & $7.3(1.31)$ \\
\hline No fixed time & $1.1(0.33)$ & $1.3(0.31)$ & $5.3(0.79)$ & $1.2(0.55)$ \\
\hline \multicolumn{5}{|l|}{ IV. Type of access to drinking water } \\
\hline 1.Standpipe & $94.3(0.94)$ & $98.9(0.30)$ & $84.8(1.18)$ & $93.3(1.31)$ \\
\hline 1.1. Personal Standpipe & $15.9(1.61)$ & $59.6(1.37)$ & $22.3(1.37)$ & $71.1(2.32)$ \\
\hline - Duration of source (less than 2 hours) & $1.2(0.44)$ & $10.7(0.86)$ & $2.3(0.52)$ & $4.4(1.00)$ \\
\hline 1.2. Non-personal Standpipe & $78.5(1.80)$ & $39.3(1.37)$ & $62.5(1.63)$ & $22.2(2.13)$ \\
\hline - Time to source (30 Minutes or more) & $23.7(1.92)$ & $4.5(0.61)$ & $23.0(1.44)$ & $4.1(1.05)$ \\
\hline - Duration of source $(<2$ hours/day) & $2.6(0.71)$ & $6.6(0.66)$ & $3.8(0.67)$ & $4.1(1.00)$ \\
\hline - Time or Duration & $25.2(1.95)$ & $10.6(0.85)$ & $25.3(1.49)$ & $7.4(1.36)$ \\
\hline 2. Borehole/ Tube well & $14.2(1.39)$ & $1.8(0.39)$ & $20.3(1.37)$ & $10.5(1.56)$ \\
\hline 2.1. Personal Borehole/Tube well & $10.3(1.47)$ & $0.4(0.20)$ & $0.4(0.22)$ & $0.1(0.05)$ \\
\hline 3. Non-improved Water Source ${ }^{39}$ & $9.2(1.03)$ & $2.3(0.43)$ & $11.3(1.03)$ & $9.7(1.54)$ \\
\hline \multicolumn{5}{|l|}{ V. Type of cooking fuel and place of } \\
\hline LPG User & $47.1(2.21)$ & $86.6(0.97)$ & $93.8(0.85)$ & $98.2(0.67)$ \\
\hline Kerosene User & $94.7(0.88)$ & $37.2(1.39)$ & $3.0(0.59)$ & $0.0(0.00)$ \\
\hline Biomass Fuel User & $11.2(1.35)$ & $0.7(0.25)$ & $11.1(1.11)$ & $4.6(1.08)$ \\
\hline Outdoor Cooking & $22.3(1.90)$ & $0.3(0.15)$ & $7.2(0.91)$ & $2.0(0.73)$ \\
\hline Inside Sleeping Room & $46.8(2.26)$ & $65.0(1.36)$ & $73.1(1.55)$ & $39.0(2.51)$ \\
\hline - With chimney/exhaust & $2.0(0.60)$ & $26.0(1.26)$ & $21.1(1.43)$ & $15.1(1.86)$ \\
\hline - Close to window & $26.0(1.99)$ & $21.4(1.19)$ & $20.1(1.39)$ & $16.8(1.92)$ \\
\hline - No smoke outlet & $18.6(1.90)$ & $17.6(1.11)$ & $31.9(1.63)$ & $7.2(1.38)$ \\
\hline Separate Kitchen & $30.5(2.05)$ & $34.0(1.36)$ & $18.9(1.37)$ & $59.0(2.52)$ \\
\hline
\end{tabular}

\footnotetext{
39 Unimproved water sources include tanker truck, small cart, bottled water (not mineral water), surface water
} (river/pond/lake) and other sources. 


\section{Drinking Water:}

We next look at the access to drinking water source. Households in slums use multiple water sources. Our findings suggest that members from more than $90 \%$ of households in Kolkata, Mumbai and RR colonies use standpipes, which are of two types: personal standpipes and non-personal standpipes. Although slums in Mumbai have the highest coverage to standpipes, slums in RR colonies appear to have the highest coverage of personal standpipes; whereas slums in Kolkata have the lowest coverage of personal standpipes. In slums however collecting drinking water from standpipes - personal or non-personal - is not enough, and it is crucial to explore the travelling and waiting time to the water source as well as the duration of the water source. Members in nearly $23 \%$ of households in slums of Kolkata and JJ clusters of Delhi use non-personal standpipes are required to travel or wait 30 minutes or more in order to access the water source. Slums in Mumbai and RR colonies do not have this problem, but looking at the duration of source we find that members in 17.3\% households in Mumbai and $8.3 \%$ households in RR colonies use standpipes and have access to water only for less than 2 hours per day. In Mumbai, note that, members of only $4.5 \%$ households use standpipes and need to travel or wait for 30 minutes or more for the water source, but an additional 16.8\% $(10.7 \%+10.6 \%-$ $4.5 \%$ ) households use standpipes and have access to the source for less than two hours a day. Lastly, in Kolkata and Delhi, 9-11\% households use at least one non-improved source of drinking water.

\section{Cooking Fuel \& Kitchen:}

We finally look at the type of cooking fuels used by the households and the places where the food is cooked. The two types of cooking fuel that are mainly used in the slums of these three cities are Kerosene and Liquid Petroleum Gas (LPG). However, the use of any form of biomass fuel is not completely uncommon. In slums of Kolkata and JJ clusters nearly $11 \%$ of all households and in RR colonies around $4.6 \%$ of households use some type of biomass fuel for cooking purposes. Although the proportions of Kerosene users are negligible in Delhi, its use is prevalent among the households in Mumbai (37\%) and is predominant in Kolkata (94.7\%). The uses of biomass fuel and to a lesser extent the uses of Kerosene may result in various kinds of health hazards to household members. These hazards may become worse depending on where food is cooked within households.

Food may be cooked either at a separate kitchen within a household, or inside the living room or outside of the house. In urban setting, cooking outside of house or cooking within the same room used for sleeping also reflects the poorer socio-economic status of the household. In Kolkata, for more than a fifth $(22.3 \%)$ of all households cooking takes place outside of house and for $44.6 \%$ of households cooking takes place inside sleeping room without chimneys and exhaust fans. Outdoor cooking is not 
so common in other two cities, but cooking inside the sleeping rooms without chimneys takes place in many households of Delhi's JJCs (52\%), Mumbai slums (39\%) and Delhi RR colonies (23.9\%).

Table 6: Possession of Assets by Slum Dwellers in Three Cities

\begin{tabular}{|c|c|c|c|c|c|c|c|}
\hline \multirow[t]{2}{*}{ Assets } & \multicolumn{2}{|c|}{ Kolkata } & \multicolumn{2}{|c|}{ Mumbai } & \multicolumn{2}{|c|}{ Delhi JJ } & Delhi RR \\
\hline & $(\%)$ & $(\mathrm{SE})$ & $(\%)$ & $(\mathrm{SE})$ & $(\%)$ & $(\mathrm{SE})$ & $(\%) \quad(\mathrm{SE})$ \\
\hline Television (\%) & 86.4 & $(1.55)$ & 91.9 & $\overline{(0.79)}$ & 83.8 & $\overline{(1.30)}$ & $96.9(0.90)$ \\
\hline Refrigerator (\%) & 26.0 & $(2.01)$ & 59.9 & $(1.41)$ & 44.9 & $(1.73)$ & $78.4(2.12)$ \\
\hline Washing Machine (\%) & 2.2 & $(0.64)$ & 23.5 & (1.23) & 18.2 & (1.34) & $38.4(2.49)$ \\
\hline Computer $(\%)$ & 7.2 & $(1.12)$ & 20.6 & $(1.17)$ & 4.9 & $(0.77)$ & $13.3(1.72)$ \\
\hline Cell Phone (\%) & 92.5 & $(1.25)$ & 96.9 & $(0.51)$ & 94.5 & $(0.77)$ & $97.8(0.71)$ \\
\hline Adult Person per Cell Phone & 1.9 & & 1.5 & & 2.3 & & 1.8 \\
\hline Motorbike $(\%)$ & 7.8 & $(1.10)$ & 19.6 & (1.14) & 15.0 & $(1.25)$ & $36.2(2.46)$ \\
\hline Four Wheeler (\%) & 0.3 & $(0.17)$ & 2.5 & $(0.46)$ & 0.7 & $(0.29)$ & $4.3(1.04)$ \\
\hline Chair $(\%)$ & 49.2 & $(2.27)$ & 55.8 & (1.44) & 32.8 & (1.64) & $73.4(2.25)$ \\
\hline Bed for sleeping (\%) & 88.7 & $(1.35)$ & 65.8 & $(1.36)$ & 79.2 & (1.41) & $95.4(1.11)$ \\
\hline
\end{tabular}

\section{Asset Holding:}

Finally, we present the possession of certain assets in slums in Table 6. The asset that has the highest coverage across households is cell phone. Between 92-98\% households in all cities have at least one member possessing a cell phone, but the density of cell phone ownerships varies across cities. While in Mumbai there are 1.5 adult persons per cell phone, there are 2.3 adult members per cell phone in Delhi's JJ cluster. For the rest of the assets, the incidence of possession is highest in Delhi's RR colonies except computers in which Mumbai has the highest incidence. The incidence of asset ownerships in Mumbai and RR colonies are much higher than the corresponding asset ownerships in Kolkata and Delhi's JJ clusters. Strikingly, in Mumbai, the incidence of possessing beds for sleeping is the lowest $(66 \%)$. The reason behind this phenomenon might be the higher incidence of cooking inside rooms without proper smoke outlay (around 39\% households reported this, see the last panel of Table 5 above) in relatively smaller and single-room sets in Mumbai.

\section{Migrant Status and Mutiple Material Deprivations}

To continue with our discussion of material well-being from the previous section, in this section we now analyse multidimensional material deprivation. In urban slum areas, the dwellers face multidimensional deprivations that are invariably associated with living conditions (e.g. poor quality housing, often in overcrowded unsanitary slum settlements, and with ill health), fairly fragile and thin asset base, limited or no access to a wider range of services (including health, education and law and order), and a high dependence on labour markets, complex social relationships. Often times, deprivations are associated with specific subgroup of people. The levels of urban deprivations are 
exacerbated by the discriminatory practices operated by the legal authorities (e.g. local governments, judicial systems, etc) and their failure to keep pace with the growing demands for settlements.

Table 7: Indicators of Material Deprivation and the Percentage of Households Deprived in them

\begin{tabular}{|c|c|c|c|c|c|c|}
\hline \multirow[b]{2}{*}{ Indicators } & \multirow{2}{*}{$\begin{array}{c}\text { Deprivation Condition } \\
\text { (A household is deprived in the indicator if ...) }\end{array}$} & \multicolumn{5}{|c|}{ Proportion of Deprived Households (\%) } \\
\hline & & Kolkata & Mumbai & $\begin{array}{c}\text { Delhi } \\
\text { Overall }\end{array}$ & $\begin{array}{c}\text { Delhi } \\
\text { JJ }\end{array}$ & $\begin{array}{c}\text { Delhi } \\
\text { RR }\end{array}$ \\
\hline Over-crowding & $\begin{array}{l}\text { Any household has three or more members per } \\
\text { bedroom }{ }^{40}\end{array}$ & 71.20 & 71.20 & 67.30 & 72.40 & 60.90 \\
\hline Housing type & $\begin{array}{l}\text { Any house is semi-pucca or kutcha; or the } \\
\text { household lives in a temporary accommodation } \\
\text { without any proper house }\end{array}$ & 76.00 & 46.90 & 34.20 & 53.40 & 10.40 \\
\hline $\begin{array}{l}\text { Leakage in } \\
\text { house }\end{array}$ & $\begin{array}{l}\text { Any household who lives in a house where } \\
\text { water leaks in the house through roof or ground }\end{array}$ & 39.10 & 29.10 & 31.20 & 39.80 & 20.60 \\
\hline $\begin{array}{l}\text { Cooking } \\
\text { Arrangement }\end{array}$ & $\begin{array}{l}\text { Any household who uses biomass fuel for } \\
\text { cooking, or cooks outdoor, or cooks inside } \\
\text { sleeping room with no smoke outlet }\end{array}$ & 45.40 & 18.60 & 29.50 & 43.00 & 12.80 \\
\hline Sanitation & $\begin{array}{l}\text { Any household without any personal sanitation } \\
\text { facility, or the personal facility is shared with } \\
\text { other households }\end{array}$ & 83.40 & 74.90 & 53.20 & 81.50 & 18.20 \\
\hline Water Source & $\begin{array}{l}\text { Any household with non-improved water source, } \\
\text { or with standpipe facility but time to the water } \\
\text { source is more than } 30 \text { minutes, or with } \\
\text { standpipe facility but the supply duration is less } \\
\text { than two hours per day }\end{array}$ & 21.50 & 10.20 & 22.60 & 29.10 & 14.70 \\
\hline Communication & $\begin{array}{l}\text { Any household that does not have a landline } \\
\text { phone; and the number of cell-phones within the } \\
\text { household is less than the number of its } \\
\text { members in the age group of } 22-64 \text { years }\end{array}$ & 59.90 & 37.40 & 59.40 & 64.10 & 53.60 \\
\hline Assets & $\begin{array}{l}\text { Any household having none of the major assets: } \\
\text { refrigerator, computer, washing machine, four } \\
\text { wheeler, AC/cooler }\end{array}$ & 71.60 & 34.00 & 23.30 & 32.20 & 12.30 \\
\hline
\end{tabular}

After examining the various indicators of material well-being separately in section 5 , in this section, we aim to explore the joint distribution of material deprivations faced by the urban dwellers categorizing them across various migration categories discussed in the section $4 .{ }^{41}$ Based on comparable cross-city indicators available in our survey, we select eight indicators, which are presented in Table 9. The first column of the table reports the eight indicators, the second column reports the deprivation curoff of each indicator, and the final five columns report the proportion of slum households deprived in each of the eight indicators in different cities. These indicators can be grouped into three broad categories - housing (over-crowding, structure of house, housing leakages, and cooking arrangements/ fuel usages), provision of basic service (access to improved sanitation facility and improved water sources), asset-ownership (includes the ownership of major assets and the

\footnotetext{
40 This indicator is based on the UN-HABITAT (2006) guideline.

${ }^{41} \mathrm{We}$ are also interested in exploring multidimensional poverty (involving deprivations in other non-monetary/non-material dimensions of well-being) in urban settings and examine its associated attributes through regression analysis. This requires in-depth research due to the existence of high level of potential endogeneity. We aim to explore these issues in a companion paper.
} 
possession of a means of communication through landline phones or cell-phones). A household is considered deprived in an indicator if the household meets the deprivation condition of the corresponding indicator listed in the second column of Table 9. Although the incidences of deprivation (the proportion of households deprived) vary across cities, the incidence is lowest in the water indicator and highest in the sanitation and the over-crowding indicators.

Once the deprivations of each household are identified, we construct a material-deprivation score for every slum dwelling household in our survey by simply counting their deprivations in the eight indicators. ${ }^{42}$ The average material-deprivation scores are reported in Table 8 . By computing the deprivation scores considering all possible deprivations, we technically use a union approach to identify the poor households.

The average deprivation score is highest in Kolkata (4.7), followed by (in order) Delhi's JJ clusters (4.2), Mumbai (3.2) and Delhi's RR colonies (2.0). ${ }^{43}$ The dwellers of Delhi RR colonies are the least deprived ones amongst all, because of their ownership status of the plot of land and relatively better access to the civic facilities. It is worth noting that the average deprivation scores of the slum dwelling households of Kolkata and Delhi's JJ clusters are very close to each other (which we have been noticing throughout in various sections of this paper). Moreover, incidences of deprivation in slums of Kolkata and Delhi's JJ clusters are close to each other and reasonably high for sanitation indicator (more than 80\%), whereas close and moderately high for the indicator of cooking arrangements (over 40\%) (see Table 5). Despite their similarilties, sources of deprivations are quite different. Although slum dwellers in over $67 \%$ of households in Kolkata and Delhi JJ use publicly shared provided toiltets, in Kolkata the time to access the facility is much lower (upto 1 minute for $66 \%$ housheolds) than that in Delhi JJ (where more than $47 \%$ people reported time to access is higher than 5 minutes) (see Table 5). Furthermore, the incidence of deprivation in cooking arrangement also differ in nature in these two cases - in Kolkata because of more incidence of use of Kerosene and biomass fuel (97\%), whereas in Delhi more people are cooking inside the sleeping room. However, Kolkata slum dwellers are far more deprived than their counterparts of other cities in two indicators - housing type and asset ownership.

Who are more deprived in these indicators? In this subsection, we aim to briefly study materialdeprivations across different migration categories. Especially, we ask whether the earlier migrants are

\footnotetext{
${ }^{42}$ See Alkire and Foster (2011) for an axiomatic framework for counting deprivations and measuring poverty. Simply counting the deprivations is equivalent to assigning equal weights to all deprivations. For an application of the counting approach using unequal weights to measure multidimensional poverty in the Indian context, see Alkire and Seth (2015). Counting deprivations to identify poor as well as measuring poverty have been used in different part of the world including Europe, Latin America, and Asia. For an overview of historical applications of counting approaches, see Chapter 4 of Alkire et al. (2015).

43 We have undertaken test of significance for pairwise differences in mean values, and shows that intercity differences in mean scores of deprivation are significant.
} 
more materially deprived or the more recent migrants and whether the households whose heads are born in the city are more materially derpived or the households with presently migrant heads? To find answers to these questions, we next look at the deprivation scores in each city by dividing the households in different migration categories. In the first categorization, we divide the household by whether the household head was born in the city or whether the head migrated to the city at some point in time. We observe a consistent pattern across cities. The average material-deprivation scores are statistically significantly higher among those for who the head has migrated than those for who the head was born in the city. This finding is quite striking and calls for further investigation. In order to explore further we consider two additional classifications of migrants over time. In one case, we classify only those households based on their time of migration where the existing household-heads themselves are migrants (we exclude those households where the heads were born in the city). In the other case, we classify all households based on their time of migration occurred at any generation (irrespective of whether the head of the household was born or migrated - similar in spirit to the analysis based on Figure 1).

Table 8: The average material-deprivation score for different cities and migration categories

\begin{tabular}{|c|c|c|c|c|c|c|c|}
\hline & \multicolumn{2}{|c|}{ Kolkata } & \multicolumn{2}{|c|}{ Mumbai } & \multicolumn{2}{|c|}{ Delhi JJ } & Delhi RR \\
\hline I. Overall & 4.7 & $(0.07)$ & 3.2 & $(0.05)$ & 4.2 & $(0.05)$ & $2.0 \quad(0.08)$ \\
\hline \multicolumn{8}{|c|}{ II. By Migrated/Born in the city } \\
\hline Migrated & 4.9 & $(0.11)$ & 3.4 & $(0.06)$ & 4.2 & $(0.06)$ & $2.1(0.10)$ \\
\hline Born in the City & 4.6 & $(0.10)$ & 3.0 & $(0.08)$ & 4.0 & $(0.14)$ & $1.9(0.11)$ \\
\hline Difference & \multicolumn{2}{|c|}{$0.3^{* * *}$} & \multicolumn{2}{|c|}{$0.4^{* * *}$} & \multicolumn{2}{|c|}{$0.2^{* *}$} & $0.2^{* *}$ \\
\hline
\end{tabular}

II. A. By the time of migration

(Only if the head is a migrant)

\begin{tabular}{llllllll} 
(i) Before 1970 & 4.9 & $(0.19)$ & 3.0 & $(0.13)$ & 3.7 & $(0.25)$ & $1.8(0.14)$ \\
(ii) 1971-1990 & 5.0 & $(0.15)$ & 3.3 & $(0.08)$ & 4.1 & $(0.07)$ & $2.1(0.14)$ \\
(iii) After 1990 & 4.7 & $(0.26)$ & 3.8 & $(0.12)$ & 4.4 & $(0.11)$ & $2.4(0.27)$ \\
Difference $($ ii - i) & 0.0 & & $0.3^{* *}$ & $0.4^{* *}$ & $0.3^{* *}$ \\
Difference $($ iii - ii) & $-0.3^{*}$ & & $0.5^{* * *}$ & $0.2^{* *}$ & $0.3^{*}$ \\
Difference $($ iii - i) & -0.2 & & $0.8^{* * *}$ & $0.6^{* * *}$ & $0.6^{* *}$ \\
\hline
\end{tabular}

III. By the time of migration (Any generation)

\begin{tabular}{llllllll}
\hline (i) Before 1970 & 4.6 & $(0.09)$ & 3.0 & $(0.07)$ & 3.9 & $(0.12)$ & $1.9(0.09)$ \\
(ii) 1971-1990 & 5.0 & $(0.15)$ & 3.3 & $(0.08)$ & 4.2 & $(0.08)$ & $2.2(0.14)$ \\
(iii) After 1990 & 4.6 & $(0.25)$ & 3.8 & $(0.12)$ & $4.3(0.10)$ & $2.3(0.25)$ \\
\hline Difference $(i i-i)$ & $0.4^{* * *}$ & $0.3^{* * *}$ & $0.3^{* *}$ & $0.3^{* *}$ \\
Difference $($ iii - ii) & $-0.4^{* *}$ & $0.5^{* * *}$ & $0.2^{*}$ & 0.2 \\
Difference $($ iii $-i)$ & 0.0 & $0.8^{* * *}$ & $0.4^{* * *}$ & $0.5^{\text {*** }}$ \\
\hline
\end{tabular}

Standard errors are reported in the parentheses.

***-Statistically significant at $\alpha=1 \%,{ }^{* *}$-Statistically significant at $\alpha=5 \%,{ }^{*}$-Statistically significant at $\alpha=10 \%$ and n.s.- Not statistically significant.

Based on our next classification, the households with migrant heads (excludes those where the head was self-reported to be born in the city) are divided into three categories: those who migrated before 1970, those who migrated between 1971-1990 and those who migrated after 1990. Average 
deprivation scores of these households in each migration category are reported in panel II.A of Table 8. In Mumbai and Delhi, we observe that the time of migration matters. Those who migrated earlier in the city tended to be less materially deprived than those who migrated in later phases. These differences in material-deprivation scores are statistically significant. Kolkata is however exception to this trend, but why? We elaborate more on this matter in the next paragraph after presenting deprivation scores for the other classification.

Finally, we classify all the households (including all, irrespective of the head was born or migrated) into the same three categories as above. In panel III of Table 8, we again find a pecking order of higher mean deprivation score for the more recent migrant households in Mumbai and Delhi. Kolkata again is an aberration to this trend. Unfortunately, those who migrated between 1971-90 are facing higher rate of deprivations compared to the other two groups who are exactly on equal footing. A significant chunk of people who migrated to Kolkata during 1971-90 were Bangladeshi Refugee, who were settled in many unorganised, inappropriately planned refugee colonies, scattered across the city, (perhaps, Bengal's the-then political crisis of 1970s also played a crucial role in this haphazard settlement process). Irony is that these settlements are still langushing in despair without much help from civic authorities. But a fact that the migrants of the other two groups (before 1970 and after 1990) are facing the same material deprivation is quite striking and calls for more attention and detailed research. An apparent explation to this, drawing cues from the historical facts in section 4 , this is a classic case of stagnancy in aquiring material welbeing and chronic deprivation that the slum dwellers of Kolkata have been facing. However, why recently migrants are more materially deprived than early migrants require further rigorous reseach. We are conducting research on this issue in a companion paper.

\section{Monetary Dimensions}

We now delineate another prime indicator of living condition - the monetary achievements, which is primarily assessed through two competing approaches - the income approach or the consumption expenditure approach. In income approach, a person's economic achievement is measured by the access to the maximum possible monetary resources that a person is able to spend without depleting the assets held (income); whereas the consumption approach considers the total consumption of goods and services valued at current prices, regardless whether an actual transaction has taken place (consumption expenditure). The assessment of monetary achievements through either approach has its own advantages and disadvantages. The main advantage of income approach is its ability to capture the spending capacity of a household. However, there are certain disadvantages, especially in the developing country context, such as incomes are subject to large seasonal fluctuations and the data accuracies of wage earnings, a major component of incomes, are difficult to verify as a large fraction 
of the population is employed in informal sectors. The consumption expenditure data on the other hand are likely to provide more accurate information, but the primary disadvantage of this approach is the recall period, which may affect the overall expenditure.

Our survey datasets contain brief modules on household income from employment and other sources as well household expenditure on various accounts. The income module contains information on employment wage earnings, inward remittances and rents received from property ownerships; whereas, the expenditure module includes information on consumption and expenses incurred on major food items, cooking fuel and intoxicants, and payments made for rent, electricity bills, and outward remittances. ${ }^{44}$ Note that the income and consumption expenditure data in our survey are comparable across three cities and so are the statistics generated, but our statistics may not be strictly comparable with those obtained from other major data sources, such as those in National Sample Surveys and in other national accounts.

In Table 9, we present sizes and spreads of the distributions of monetary achievements in slums of three cities. We assess the size of each distribution by two measures: the mean and the median; whereas the spread or inequality within each distribution is assessed by three measures: the Gini coefficient, the 90/10 Ratio and the 75/25 Ratio. ${ }^{45}$ Note that both mean and Gini are based on the entire distribution of achievements and thus are likely to be affected by extreme values or outliers, thus we additionally report median, 90/10 Ratio and 75/25 Ratio that are robust to outliers.

We find that the size of the distribution of monetary achievements - measured by the mean and the median per capita income and that of the expenditure - is highest in slums of Mumbai, followed by Delhi and then Kolkata. Within Delhi however the size of the distribution in RR colonies is much higher than that in JJ clusters. In fact, the size of the distribution, especially the per capita income, in $\mathrm{JJ}$ clusters of Delhi is very similar to the size of the distribution in slums of Kolkata. Looking at the inequality measures, we find the levels of inequality to be very similar across slums in all three cities although the sizes are quite different. The Gini coefficients of per capita income in all three cities lie between 33.4 and 36.3; whereas the Gini coefficients of per capita expenditure lie between 22.5 and 24.6. The two other inequality measures also lead to the similar conclusions. If we divide the slums in

\footnotetext{
${ }^{44}$ Total expenditure of households does not include education fees for students, the cost of clothing, water, and sanitation, the transport cost for the students and the employed persons, and the expenditure on food consumed outside of the house.

${ }^{45}$ Each inequality measure (let us denote by $I$ ) is a function of two standards $a$ and $b$ such that $I=(a-b) / a$, where $a>b$. In other words, each inequality measure may be presented as a relative (percentage) short fall of the lower standard $b$ from the higher standard $a$ and so $I \in[0,100]$. A value of $I=60$ implies that the difference between the higher and the lower income standards is sixty percent of the higher income standard. In extremes, a value of $I=0$ denotes the absence of inequality within a distribution; whereas a value of $I=100$ denotes the highest level of inequality within the distribution. A higher value of $I$ represents a larger level of inequality. For the Gini coefficient, the higher standard is the mean and the lower standard is the Sen mean; for the 90/10 Ratio, the higher standard is the 90th percentile and the lower standard is the 10th percentile; and for the 75/25 Ratio, the higher standard is the 75th percentile and the lower standard is the 25th percentile. For detailed discussions on this issue, see Foster, Seth, Lokshin and Sajaia (2013).
} 
Delhi into JJ clusters and RR colonies, then inequality in per capita income appears to be slightly higher in RR colonies, whereas inequality in per capita expenditure appears to be slightly higher in JJ clusters. Thus, the levels of inequality are more or less similar across the slums of three cities, but the sizes of the distributions are different. The per capita consumption expenditure (based on the items in our survey) appears to be highest in Mumbai as well.

Table 9: Monthly Per Capita Income, Consumption Expenditure and Inequality

\begin{tabular}{|c|c|c|c|c|c|}
\hline & Kolkata & Mumbai & Delhi & Delhi JJ & Delhi RR \\
\hline \multicolumn{6}{|c|}{ Per Capita Income ${ }^{46}$ (in Rs.) } \\
\hline Mean & 2638.8 & 4166.3 & 3216.5 & 2675.9 & 3887.6 \\
\hline Median & 2072.1 & 3221.3 & 2510.9 & 2226.4 & 3013.1 \\
\hline \multicolumn{6}{|c|}{ Inequality in Per Capita Income } \\
\hline Gini Coefficient & 36.3 & 35.4 & 33.4 & 29.8 & 34.0 \\
\hline 90/10 Ratio & 78.8 & 78.7 & 77.0 & 72.4 & 75.5 \\
\hline 75/25 Ratio & 54.4 & 55.1 & 52.6 & 47.3 & 55.1 \\
\hline \multicolumn{6}{|c|}{ Per Capita Consumption Expenditure (in Rs.) } \\
\hline Mean & 1367.3 & 1592.7 & 1495.8 & 1441.2 & 1563.6 \\
\hline Median & 1252.2 & 1376.1 & 1374.7 & 1289.7 & 1476.5 \\
\hline \multicolumn{6}{|c|}{ Inequality in Per Capita Expenditure } \\
\hline Gini Coefficient & 24.3 & 24.6 & 22.5 & 24.0 & 20.3 \\
\hline 90/10 Ratio & 66.0 & 65.7 & 61.9 & 63.3 & 58.3 \\
\hline 75/25 Ratio & 43.5 & 40.8 & 39.5 & 42.1 & 36.4 \\
\hline
\end{tabular}

The distributions of per capita expenditure across different items (or components) are however quite different across cities. Table 10 presents the distribution of per capita consumption expenditure for a representative person in Kolkata, in Mumbai, in Delhi JJ clusters and in Delhi RR colonies. The first column of the table reports different components of per-capita consumption expenditure. The first column in each city reports the per capita expenditures spent on each item; the second column reports the corresponding standard errors; and the third column reports the percentage share of total per capita expenditure spent on different items.

Although market prices play a crucial role in determining this variation of expenditure across different items, the role of slum dwellers' preferences and public policies (towards PDS schemes and prices) cannot be ignored. At the time of the survey, Delhi Government had already adopted a universal PDS scheme (rice, wheat and sugar for all card types), whereas in Mumbai and Kolkata were running the old PDS schemes, which was mainly directed to BPL (below the poverty line) population [Kerosene is provided for all card types, but rice, wheat, sugar only for BPL]. Moreover, the outreach and distribution pattern of cardholding population is quite different in these cities [see, the upper panel of the table in Appendix B for the distribution of cardholding surveyed households]. Given the

\footnotetext{
${ }^{46}$ The per capita income is computed based on the households reporting their incomes. Income data were reported for $98.5 \%$
} households in Kolkata, 99.7\% households in Mumbai and Delhi JJ colonies and 99.5\% households in Delhi RR colonies. 
differences in respective government's policies and the distribution pattern of various types of PDS cardholding households in three cities, the total subsidy amount received by the surveyed households in the three cities also varies. This might be having an impact on the preferred consumption mix (from market and PDS) and that in turn might be translated into the differences in overall per capita expenditure (through income as well as substitution effects).

\section{Table 10: Distribution of Monthly Mean Per Capita Consumption Expenditure across Components in Slums of Three Cities}

\begin{tabular}{|c|c|c|c|c|c|c|c|c|c|c|c|}
\hline \multirow{2}{*}{$\begin{array}{l}\text { Expenditure (Rs.) } \\
\text { on Items }\end{array}$} & \multicolumn{3}{|c|}{ Kolkata } & \multicolumn{3}{|c|}{ Mumbai } & \multicolumn{3}{|c|}{ Delhi JJ } & \multicolumn{2}{|l|}{ Delhi RR } \\
\hline & Rs. & (S.E) & Share & Rs. & $(\mathrm{S} . \mathrm{E})$ & Share & Rs. & (S.E) & Share & Rs. (S.E) & Share \\
\hline Mean Per Capita Exp. & 1367.3 & $(30.9)$ & $100 \%$ & 1592.7 & $(22.1)$ & $100 \%$ & 1441.2 & $(22.6)$ & $100 \%$ & $1563.6(31.7)$ & $100 \%$ \\
\hline (1) Rent Paid & 40.8 & $(3.7)$ & 3.0 & 133.4 & $(9.9)$ & 8.4 & 30.9 & $(3.7)$ & 2.1 & $68.0(10.0)$ & 4.3 \\
\hline (2) Electricity Bill & 124.7 & (4.9) & 9.1 & 177.5 & (3.5) & 11.1 & 163.3 & (4.3) & 11.3 & $236.1 \quad(8.8)$ & 15.1 \\
\hline (3) Outward Remittances & 49.6 & $(10.1)$ & 3.6 & 85.5 & (9.9) & 5.4 & 73.8 & (8.4) & 5.1 & $39.2(10.7)$ & 2.5 \\
\hline (4) Cooking Fuel & 111.0 & $(3.2)$ & 8.1 & 108.0 & $(2.0)$ & 6.8 & 95.9 & $(2.2)$ & 6.7 & $103.1 \quad(3.7)$ & 6.6 \\
\hline (4.1) LPG & 36.8 & $(2.0)$ & 2.7 & 80.8 & $(1.5)$ & 5.1 & 89.0 & $(2.1)$ & 6.2 & 100.9 & 6.5 \\
\hline (4.2) Kerosene & 64.9 & (3.2) & 4.7 & 22.1 & (1.5) & 1.4 & 3.6 & $(1.0)$ & 0.2 & $(0.0)$ & 0.0 \\
\hline (5) Food & 996.3 & $(22.8)$ & 72.9 & 1042.2 & $(12.2)$ & 65.4 & 993.4 & $(14.2)$ & 68.9 & $1054.9(20.6)$ & 67.5 \\
\hline (5.1) Grocery Items & 343.2 & $(5.7)$ & 25.1 & 365.9 & (3.9) & 23.0 & 320.8 & $(4.0)$ & 22.3 & $343.0 \quad(5.9)$ & 21.9 \\
\hline Sugar & 22.2 & $(0.8)$ & 1.6 & 36.6 & $(0.6)$ & 2.3 & 33.4 & $(0.8)$ & 2.3 & $(1.2)$ & 2.8 \\
\hline Pulses & 45.2 & (1.7) & 3.3 & 61.7 & (1.3) & 3.9 & 58.6 & (1.3) & 4.1 & (1.8) & 3.8 \\
\hline Oil & 76.2 & (1.6) & 5.6 & 79.8 & (1.3) & 5.0 & 81.2 & (1.3) & 5.6 & $(2.0)$ & 5.6 \\
\hline Cereals & 199.6 & $(3.8)$ & 14.6 & 185.8 & $(2.5)$ & 11.7 & 147.6 & (2.4) & 10.2 & $153.3 \quad(3.8)$ & 9.8 \\
\hline (5.2) Other Food Items & 644.7 & $(20.7)$ & 47.2 & 672.2 & (10.2) & 42.2 & 667.6 & $(12.0)$ & 46.3 & $706.5(17.5)$ & 45.2 \\
\hline Vegetables & 266.1 & $(7.6)$ & 19.5 & 270.3 & $(4.5)$ & 17.0 & 314.4 & $(5.5)$ & 21.8 & $299.0 \quad(7.1)$ & 19.1 \\
\hline Non-Vegetables & 304.5 & $(15.1)$ & 22.3 & 214.4 & $(6.5)$ & 13.5 & 143.4 & (6.2) & 9.9 & 117.0 & 7.5 \\
\hline Milk & 61.2 & $(3.5)$ & 4.5 & 162.2 & (3.5) & 10.2 & 174.7 & (4.1) & 12.1 & 242.9 & 15.5 \\
\hline Ghee & 6.6 & (1.1) & 0.5 & 18.6 & (1.4) & 1.2 & 22.3 & (1.7) & 1.6 & 35.1 & 2.2 \\
\hline Yogurt & 6.4 & $(1.2)$ & 0.5 & 6.7 & $(0.6)$ & 0.4 & 12.9 & (1.3) & 0.9 & (1.8) & 0.8 \\
\hline Baby-Food & 8.4 & $(1.5)$ & 0.6 & 4.1 & $(0.5)$ & 0.3 & 5.0 & $(0.6)$ & 0.3 & (1.1) & 0.3 \\
\hline (6) Intoxicants & 45.0 & $(6.1)$ & 3.3 & 46.1 & $(4.4)$ & 2.9 & 83.9 & $(6.8)$ & 5.8 & $(8.2)$ & 4.0 \\
\hline
\end{tabular}

Note: Rupee figures are adjusted for inter city CPI differences for various months of survey (base: Delhi October 2014)

Let us first look at the first two items - expenditure on rent and expenditure on electricity bill. The higher prices of housing in Mumbai have resulted in higher rent. The share of rent to the overall per capita expenditure in Mumbai is $8.4 \%$, however the share of rent ranges between 2.1 and $4.3 \%$ only in Delhi and Kolkata, but for completely different reasons though. In Kolkata although a higher proportion of people are living in rented accommodation (almost 62\%) vis-à-vis Delhi JJ and RR (13\% to 16\%) (see, Table 4), the rent in Kolakata is much lower (especially for Thika Tenants, as low as Rs. 20 per month) than that of in Delhi JJ and RR (at least Rs. 3000 per month). The expenditure on electricity bills, however, is highest in Delhi's RR colonies, (an apparent reason for this could be the much higher possession of electricity consuming assets, see Table 6). The rent and electricity bills together, both in the slums of Mumbai and RR colonies, account for $19.5 \%$ of the per capita expenditure. The corresponding shares in Kolkata and JJ colonies of Delhi are 12.1\% and 13.4\%, respectively. What we notice is that the per capita expenditure on rent and electricity bills in Kolkata 
slums is less than half of the same in Mumbai and the expenditure on these two items in Delhi's JJ clusters is less than two-third of the same in Delhi's RR colonies.

The third item - outward remittances, however, narrates a somewhat different story and may be related to the pattern and duration of migration in different cities. It is evident from Table 1 (in demographic details section) that the share of slum dwellers (precisely, head of household) born in the city is much lower in Mumbai and Delhi JJ clusters, unlike in Kolkata. Consequently, the likelihood of household's responsibilities towards members (if any) residing at the place of origin is higher. More than $5 \%$ of the per capita expenditure is spent on outward remittances in Mumbai and JJ clusters; whereas the corresponding figure is $3.6 \%$ in Kolkata.

Looking at the fourth item - cooking fuel, we find that between 6.6-6.8\% of the per capita expenditure in slums of Mumbai and Delhi are spent on this item. The share is higher for Kolkata $(8.1 \%)$. This difference in expenditure on fuel between the slums in Kolkata and slums in other cities arises because of the predominant use of Kerosene as a source of primary cooking fuel. Of the per capita expenditure on cooking fuel in Kolkata, only a third is spent on liquid petroleum gas (LPG) and nearly 58\% is spent on Kerosene. In Mumbai slums, the share of expenditure spent on Kerosene is only one-fifth of the per capita expenditure on fuel; whereas in Delhi more than $90 \%$ of the expenditure on cooking fuel is spent on LPG.

Even though the use of Kerosene within households entails various types of health hazards (Muller $e t$ al 2003; Pokhrel et al 2010), what is the reason behind using Kerosene? One may argue that the unit price of Kerosene available through PDS (Rs. 15 per litre) is cheaper, which is evident from Table 11. However, we notice that $40 \%$ of the Kerosene is purchased from the private sources at a much higher price (Rs. 41 per litre). Despite this extra price paid for the $40 \%$ of kerosene bought from the market, why slum dwellers of Kolkata not switching to LPG? We may put forward two apparent reasons. One reason is that the Kolkata slum dwellers may be unaware of the health hazards of the Kerosene use; and second is that unlike in Delhi and Mumbai, access to LPG through public sources may not be straightforward and wealth-constrained.$^{47}$ Another notable aspect within Delhi slums is that $17-20 \%$ of LPG is purchased from private sources and the price differential between public and private sources is very large, compared to Mumbai and Kolkata. It is worth noting here that the Delhi Government around 2011 gradually started to stop providing kerosene through PDS and swapped all Kerosene PDS cards with that of LPG cylinder through a special scheme (Kerosene Free Delhi). The

47 Two factors can explain this phenomenon - (i) availability of subsidized Kerosene through PDS channel to PDS cardholders in Kolkata; (ii) this subsidized price of kerosene distorts upwardly the relative prices of other fuels (e.g. LPG) available through market or Government sources (See, Table 11). 
lack of easily available fuel substitutes thus is a strong reason behind such high a price differential in

Delhi. Other explanations require further research and beyond the scope of this paper.

\section{Table 11: Monthly Per Capita Consumption and Median Prices of Cooking Fuel and Grocery Items in Slums of Three Cities}

\begin{tabular}{|c|c|c|c|c|c|c|c|c|}
\hline \multirow[b]{2}{*}{ Items } & \multicolumn{2}{|c|}{ Kolkata } & \multicolumn{2}{|c|}{ Mumbai } & \multicolumn{2}{|c|}{ Delhi JJ } & \multicolumn{2}{|c|}{ Delhi RR } \\
\hline & $\begin{array}{l}\text { Average } \\
\text { Quantity } \\
\end{array}$ & $\begin{array}{c}\text { Median } \\
\text { Price } \\
\end{array}$ & $\begin{array}{l}\text { Average } \\
\text { Quantity } \\
\end{array}$ & $\begin{array}{c}\text { Median } \\
\text { Price }\end{array}$ & $\begin{array}{l}\text { Average } \\
\text { Quantity } \\
\end{array}$ & $\begin{array}{c}\text { Median } \\
\text { Price } \\
\end{array}$ & $\begin{array}{l}\text { Average } \\
\text { Quantity } \\
\end{array}$ & $\begin{array}{c}\begin{array}{c}\text { Median } \\
\text { Price }\end{array} \\
\end{array}$ \\
\hline \multicolumn{9}{|l|}{ Cooking Fuel } \\
\hline Kerosene (Lt.) & 2.43 & & 0.60 & & 0.06 & & 0.00 & \\
\hline From Market (Lt.) & $(40 \%)$ & 41 & $(59 \%)$ & 47 & $0.06(100 \%)$ & 51 & 0.00 & - \\
\hline From PDS (Lt.) & $(60 \%)$ & 15 & $0.25 \quad(41 \%)$ & 14 & 0.00 & - & 0.00 & - \\
\hline LPG (Kg.) & 1.20 & & 2.49 & & 2.24 & & 2.62 & \\
\hline Private (Kg.) & $(5 \%)$ & 31 & 0.17 & 30 & $0.45 \quad(20 \%)$ & 30 & $0.45(17 \%)$ & 30 \\
\hline Government (Kg.) & $1.14 \quad(95 \%)$ & 31 & $(93 \%)$ & 60 & $(80 \%)$ & 82 & $2.17(83 \%)$ & 82 \\
\hline Sugar (Kg.) & 0.55 & & 0.99 & & 1.07 & & 1.22 & \\
\hline From Market (Kg.) & $(99 \%)$ & 41 & $(99 \%)$ & 38 & $0.70 \quad(66 \%)$ & 41 & $1.10(90 \%)$ & 37 \\
\hline From PDS (Kg.) & $(1 \%)$ & 14 & $(1 \%)$ & 15 & $0.37 \quad(34 \%)$ & 14 & $0.12(10 \%)$ & 14 \\
\hline Pulse (Kg.) & 0.59 & & 0.81 & & 0.81 & & 0.77 & \\
\hline From Market (Kg.) & $0.59(100 \%)$ & 82 & $0.81(100 \%)$ & 75 & $0.81(100 \%)$ & 82 & $0.77(100 \%)$ & 82 \\
\hline From PDS (Kg.) & $0.00 \quad(0 \%)$ & 61 & $0.00 \quad(0 \%)$ & 56 & $0.00 \quad(0 \%)$ & 51 & $0.00 \quad(0 \%)$ & - \\
\hline Oil (Lt.) & 0.75 & & 0.98 & & 0.86 & & 0.93 & \\
\hline From Market (Lt.) & $0.75(100 \%)$ & 102 & $0.98(100 \%)$ & 85 & $0.86(100 \%)$ & 92 & $0.93(100 \%)$ & 93 \\
\hline From PDS (Lt.) & $0.00 \quad(0 \%)$ & 0 & $0.00 \quad(0 \%)$ & 43 & $0.00 \quad(0 \%)$ & 0 & $0.00 \quad(0 \%)$ & 0 \\
\hline Cereal (Kg.) & 7.71 & & 7.34 & & 7.80 & & 7.50 & \\
\hline - Of which Rice (Kg.) & 4.87 & & 3.56 & & 2.78 & & 2.42 & \\
\hline From Market (Kg.) & $(99 \%)$ & 29 & $(90 \%)$ & 30 & $(78 \%)$ & 26 & $2.03(84 \%)$ & 31 \\
\hline From PDS (Kg.) & $(1 \%)$ & 2 & $(10 \%)$ & 3 & $0.62 \quad(22 \%)$ & 3 & $0.38(16 \%)$ & 3 \\
\hline - Of which Wheat (Kg.) & 2.84 & & 3.78 & & 5.02 & & 5.08 & \\
\hline From Market (Kg.) & $2.71 \quad(95 \%)$ & 22 & $3.44 \quad(91 \%)$ & 24 & $3.22(64 \%)$ & 21 & $3.56(70 \%)$ & 21 \\
\hline From PDS $(K g .)^{*}$ & $(5 \%)$ & 12 & $(9 \%)$ & 7 & $1.80 \quad(36 \%)$ & 7 & $1.52(30 \%)$ & 7 \\
\hline
\end{tabular}

Note: Figures in parenthesis represent shares from source for each item. *PDS wheat price includes Rs.5 grinding charge. Rupee figures are adjusted for inter city CPI differences for various months of survey (base: Delhi October 2014)

Let us now turn to the patterns of food consumption and expenditure, which is the fifth item in Table 10. We divide the per capita expenditure on food into the expenditure on groceries and the expenditure on other food items including vegetables, non-vegetables, milk, ghee (a type of clarified butter), yogurt and baby foods. Groceries include sugar, pulses, oil and cereals (rice and wheat). We present the per capita quantity consumed and the median price of each grocery item in Table 11 . The market prices of grocery items appear to be stable across three cities, yet in Kolkata more than 58\% of the grocery expenditure is spent on cereals; whereas only $45 \%$ and $51 \%$ of the same is spent on cereals in Delhi and Mumbai. The reason for this difference is primarily due to the difference in the food preferences of the slum dwellers. It is evident from Table 10 that the per capita consumptions of three grocery items - sugar, cereal and oil - in Kolkata slums are much lower than the per capita 
consumption of the corresponding items in Mumbai and Delhi. ${ }^{48}$ It should also be noted that the expenditures of cereals are much lower in Delhi slums compared to Kolkata and Mumbai despite similar levels of per capita consumption of cereals. This is because larger shares of cereals in Delhi slums are purchased through PDS at a lower price, unlike in Mumbai and Kolkata (where the share of households possessing BPL cards is also much lower; see the table in Appendix B).

The difference in food preferences becomes much more transparent when we look at the expenditure pattern for other food items. Let us first look at the non-vegetable items that include egg, fish, chicken, meat and beef. The per capita expenditure on non-vegetable items is much higher in Kolkata slums followed by Mumbai slums, and in Delhi slums the per capita expenditure on non-vegetable items is less than half of that in Kolkata. The pattern of lower per capita expenditure on non-vegetable items in Delhi complies with the findings in GoI (2014). This is related to the proportion of vegetarian households in different cities. While the proportion of pure vegetarian households is $3.5 \%$ in Kolkata slums, the proportions of the same are 17.8\% in Mumbai slums and 23.9\% in Delhi slums $(19.4 \%$ in JJ clusters and 29.4\% in RR colonies). In Mumbai and especially in Delhi, the lower consumption of non-vegetable items is compensated by much higher consumption of vegetables, milk, ghee and even pulses, which is evident from higher expenditures on these items.

Finally, the per-capita expenditure on intoxicant appears to be highest in Delhi. In JJ clusters of Delhi, the per capita expenditure on intoxicants is almost twice as high as that in slums of Kolkata.

We make certain crucial observations from our analysis in this section. Based on the income and expenditure information that we have collected, we find the level of inequality to be similar across different cities. We further find that the per capita expenditure is highest in Mumbai, followed by Delhi RR colonies, Delhi JJ clusters and then Kolkata. Difference in per capita expenditures between each pair is statistically significant. The difference in per capita expenditure between Delhi and Kolkata is largely due to the differences in expenditures on rent, electricity bills and remittances. The per capita expenditure on cooking fuel however is similar across cities. Although the food expenditure is higher in Mumbai than in Kolkata (Delhi JJ is very close to Kolkata), interestingly, the per capita expenditures on food excluding milk are much higher in Kolkata than Mumbai and Delhi JJ \& RR: Rs. 935 in Kolkata and Rs. 880 in Mumbai, Rs. 819 in Delhi JJ and Rs. 812 in Delhi RR, respectively). Despite similar price levels of groceries, differences in preferences of slum dwellers across cities lead to very different distribution of consumption expenditures across components.

\footnotetext{
${ }^{48}$ A significantly lower sugar consumption (in quantity and expenditure) by the slum dwellers in Kolkata compared to their counterparts in other two cities reveals an interesting cultural difference in food preference - in Kolkata it is a more prevalent practice to buy sugary/dessert items (the Sweets, made of milk) from market (expenditures on this has not been accounted for in our survey), whereas desserts are mostly prepared at home in other two cities. Note that the expenditure on milk is also much lower in Kolkata.
} 


\section{Educational Achievements}

In this section, we outline the educational achievements of the slum dwellers - literacy and education levels among the adults (in Table 12), and school enrolment rates among the children (in Table 13). Lastly, we discuss some related schooling characteristics (in Table 14).

\section{Educational achievements of the adults:}

In Table 12, we present the performance of adult slum dwellers in terms of literacy rates and the average years of schooling completed. We identify a person as literate if the person can read, write as well as sign. The adult literacy rate (for age group 15 years or more) is highest (nearly 90\%) in slums of Mumbai, 82-84\% in slums of Kolkata and in RR colonies of Delhi. The adult literacy rate is lowest (only 70\%) in Delhi's JJ clusters. Although the existence of statistically significant gender inequality in literacy rates is common in slums of all three cities, slums in Delhi are particularly marked with high gender inequality. The difference between male and female literacy rates in Delhi is nearly 20 percentage points. The difference between gender literacy rates is less than 7 percentage points in slums of Kolkata. The performance in education in the other indicator - the average years of schooling completed - also manifests differences across cities. The average years of education completed is highest in Mumbai, where on average a person in slum appears to have completed 8.7 years of education. The corresponding level is 8 years in Delhi RR colonies and 6.5-6.6 years in Kolkata and JJ clusters of Delhi. The high level of gender inequality in Delhi that is found for literacy rates is not visible when we look at the average years of schooling. This is due to the fact that a majority of literate male slum dwellers have only completed more than a few years of schooling.

Although a comparison across gender at the city level shows statistically significant difference, the age decomposition of educational achievement however narrates a somewhat positive story. We divide the age of the slum dwellers into three subgroups: 15-24 years, 25-49 years and 50 years or more. In all cities, literacy rates are higher among the younger group of adults. In Mumbai, the literacy rate is $99 \%$ among slum dwellers in 15-24 years age group. Although literacy rates among this age group in slums are more than $90 \%$, in JJ clusters still $9 \%$ of younger adult slum dwellers cannot read, write or sign. The gender difference in adult literacy rates is most prominent in Delhi's JJ clusters among the adults in the oldest age group. The female literacy rate among those in the age group of 50 years or more is only $14 \%$. We find similar conclusions when we look at the average years of schooling. No significant gender difference is found in the youngest group of adults in Kolkata, Mumbai, and Delhi JJCs. Although the gender difference in years of schooling is statistically significant among the youngest group of adults in RR colonies, the difference is lowest among the three age groups. Thus, in terms of literacy rates and average years of education, the performance of 
slums in Mumbai is better than the slums in other two cities. The performance of Delhi slums is similar on average to that of Kolkata, but a much higher level of gender inequality exists in Delhi.

Table 12: Educational Achievement among Adults in Slums of Three Cities

\begin{tabular}{|c|c|c|c|c|}
\hline & Kolkata & Mumbai & Delhi JJ & Delhi RR \\
\hline Literacy Rate (15 years or more) & $82.0 \%$ & $89.6 \%$ & $70.2 \%$ & $83.7 \%$ \\
\hline Male & $85.3 \%$ & $94.4 \%$ & $79.7 \%$ & $92.9 \%$ \\
\hline Female & $78.6 \%$ & $84.5 \%$ & $59.5 \%$ & $74.2 \%$ \\
\hline Difference & $6.7 \%$ & $9.9 \%$ & $20.3 \%$ & $18.7 \%$ \\
\hline Significance of difference & $* * *$ & $* * *$ & $* * *$ & $* * *$ \\
\hline Literacy Rate (15-24 years) & $94.2 \%$ & $99.0 \%$ & $91.0 \%$ & $97.5 \%$ \\
\hline Male & $92.6 \%$ & $99.5 \%$ & $92.1 \%$ & $99.3 \%$ \\
\hline Female & $95.8 \%$ & $98.3 \%$ & $89.8 \%$ & $95.6 \%$ \\
\hline Difference & $-3.2 \%$ & $1.2 \%$ & $2.2 \%$ & $3.6 \%$ \\
\hline Significance of difference & n.s. & $*$ & n.s. & $* *$ \\
\hline Literacy Rate (25-49 years) & $82.3 \%$ & $91.2 \%$ & $62.6 \%$ & $85.3 \%$ \\
\hline Male & $84.8 \%$ & $95.7 \%$ & $77.1 \%$ & $94.8 \%$ \\
\hline Female & $79.6 \%$ & $86.6 \%$ & $46.6 \%$ & $75.8 \%$ \\
\hline Difference & $5.2 \%$ & $9.1 \%$ & $30.5 \%$ & $19.0 \%$ \\
\hline Significance of difference & $* *$ & $* * *$ & $* * *$ & $* * *$ \\
\hline Literacy Rate (50 years or more) & $65.3 \%$ & $72.0 \%$ & $39.4 \%$ & $60.3 \%$ \\
\hline Male & $77.4 \%$ & $83.5 \%$ & $58.6 \%$ & $79.7 \%$ \\
\hline Female & $52.1 \%$ & $60.6 \%$ & $14.0 \%$ & $40.1 \%$ \\
\hline Difference & $25.4 \%$ & $22.9 \%$ & $44.7 \%$ & $39.6 \%$ \\
\hline Significance of difference & $* * *$ & $* * *$ & $* * *$ & $* * *$ \\
\hline Years of Schooling (15 years or more) & 6.6 & 8.7 & 6.5 & 8.0 \\
\hline Male & 7.2 & 9.5 & 7.2 & 9.1 \\
\hline Female & 5.9 & 7.9 & 5.6 & 6.9 \\
\hline Difference & 1.3 & 1.6 & 1.5 & 2.3 \\
\hline Significance of difference & $* * *$ & $* * *$ & $* * *$ & $* * *$ \\
\hline Years of Schooling (15-24 years) & 8.8 & 11.0 & 8.6 & $\mathbf{1 0 . 3}$ \\
\hline Male & 8.7 & 11.0 & 8.7 & 10.6 \\
\hline Female & 9.0 & 10.9 & 8.5 & 9.9 \\
\hline Difference & -0.3 & 0.1 & 0.2 & 0.7 \\
\hline Significance of difference & n.s. & n.s. & n.s. & $* *$ \\
\hline Years of Schooling (25-49 years) & 6.3 & 8.7 & 5.7 & 8.1 \\
\hline Male & 7.0 & 9.6 & 7.0 & 9.3 \\
\hline Female & 5.6 & 7.8 & 4.2 & 6.9 \\
\hline Difference & 1.5 & 1.8 & 2.8 & 2.4 \\
\hline Significance of difference & $* * *$ & $* * *$ & $* * *$ & $* * *$ \\
\hline Years of Schooling (50 or more years) & 4.3 & 5.5 & 3.4 & 4.8 \\
\hline Male & 5.7 & 7.0 & 4.4 & 6.8 \\
\hline Female & 2.7 & 4.1 & 2.1 & 2.6 \\
\hline Difference & 3.0 & 3.0 & 2.3 & 4.1 \\
\hline Significance of difference & $* * *$ & $* * *$ & $* * *$ & $* * *$ \\
\hline
\end{tabular}

${ }^{* * * *}$-Statistically significant at $\alpha=1 \%,{ }^{* *}$-Statistically significant at $\alpha=5 \%,{ }^{*}$-Statistically significant at $\alpha=10 \%$ and n.s.- Not statistically significant.

Educational achievements of the children:

In Table 13, we analyse educational enrolments among students, including children in the 6-14 age group. We assume dwellers in the age group of 6-21 years as potential students. Given that we assume 
the age of six years as the start of the first grade, the age of 21 is when a student should be completing fifteen years of education or obtains the undergraduate degree. According to a NFHS survey 2005-06, one fifth $(22.5 \%)$ of females and $10.8 \%$ of boys aged $\geq 6$ years in Delhi have had no education; across India this figure is $41.5 \%$ of females and $21.9 \%$ of boys. ${ }^{49}$ From our survey, we find that the enrolment rate among 6-21 years age group is around 83\% in Mumbai and in Delhi RR colonies; whereas the same in Kolkata and in Delhi JJ clusters is around 75-76\%. Although the gender difference is small and statistically significant in Mumbai, we do not find any statistically significant differences in other slums. We break down the enrolment rates in various age groups. Due to the government policy of universal primary education, the enrolment rate among 6-11 years age group is very high and ranges between $95-97 \%$ in all cities, without any statistically significant difference across gender. Although the enrolment rate in elementary education (12-14 years age-group) is still high, the enrolment rate falls drastically for the higher age groups. Among the 19-21 age-group, the enrolment rate in colleges is just above 50\% in Mumbai and in RR colonies of Delhi and even below $40 \%$ in slums of Kolkata and Delhi's JJ clusters. We should point out that we do not find any gender discrimination against women in terms of education enrolment in any of the three slums in our study. In fact, we find that the female enrolment rate among 12-14 year age-group in Delhi is statistically significantly higher.

Besides looking at educational achievements, we now compare certain characteristics of schooling among the 6-14 years age-group. First we look at the type of institutions (refer to the Table 14): government institutions and private institutions. ${ }^{50}$ In the Indian context, the educational fees in government institutions are much lower due to the higher level of subsidy, but educational fees are much higher in private schools. It is thus expected that the poorer section of the population may find it difficult to send their children to private schools. We however find different patterns in slums across cities. In Mumbai, 56.8\% of the students in the 6-14 age-group are enrolled in private schools; whereas only $38.1 \%$ of the students in the same age group are enrolled in government schools. In Delhi and in Kolkata slums, however, we find a slightly different picture. In Kolkata, nearly, 55.4\% of the students attend private schools and 39.7\% attend government school. In Delhi but a higher proportion of students are enrolled in government school. In JJ clusters, more than $80 \%$ of the students attend government school and less than $15 \%$ of the students attend private schools.

\footnotetext{
49 National Family Health Survey (NFHS-3), DHS Final Report 2005-06. http://www.nfhsindia.org

${ }^{50}$ Besides government and private institutions, there are educational institutions run by Non-Governmental Organizations and other bodies (e.g. Religious Organizations like Madrasa and Missionary Schools).
} 
Table 13: Student Enrolment Rates in Educational Institutions over different age groups in Slums of Three Cities

\begin{tabular}{|c|c|c|c|c|}
\hline & Kolkata & Mumbai & Delhi JJ & Delhi RR \\
\hline Enrolment rate (6-21 years) & $76.2 \%$ & $83.5 \%$ & $75.4 \%$ & $82.8 \%$ \\
\hline Male & $76.6 \%$ & $85.0 \%$ & $76.1 \%$ & $83.5 \%$ \\
\hline Female & $75.7 \%$ & $81.8 \%$ & $74.6 \%$ & $82.1 \%$ \\
\hline Difference & $1.0 \%$ & $3.2 \%$ & $1.4 \%$ & $1.3 \%$ \\
\hline Significance of difference & n.s. & $*$ & n.s. & n.s. \\
\hline Enrolment rate (6-11 years) & $96.6 \%$ & $97.3 \%$ & $94.9 \%$ & $97.2 \%$ \\
\hline Male & $97.2 \%$ & $97.9 \%$ & $95.6 \%$ & $98.0 \%$ \\
\hline Female & $96.1 \%$ & $96.6 \%$ & $94.1 \%$ & $96.2 \%$ \\
\hline Difference & $1.1 \%$ & $1.4 \%$ & $1.5 \%$ & $1.8 \%$ \\
\hline Significance of difference & n.s. & n.s. & n.s. & n.s. \\
\hline Enrolment rate (12-14 years) & $89.4 \%$ & $97.4 \%$ & $91.2 \%$ & $96.6 \%$ \\
\hline Male & $87.3 \%$ & $98.2 \%$ & $88.0 \%$ & $94.1 \%$ \\
\hline Female & $92.2 \%$ & $96.6 \%$ & $94.4 \%$ & $100.0 \%$ \\
\hline Difference & $-4.9 \%$ & $1.6 \%$ & $-6.4 \%$ & $-5.9 \%$ \\
\hline Significance of difference & n.s. & n.s. & $* *$ & $* *$ \\
\hline Enrolment rate $(6-14$ years $)$ & $93.8 \%$ & $97.3 \%$ & $93.6 \%$ & $97.0 \%$ \\
\hline Male & $93.1 \%$ & $98.0 \%$ & $93.0 \%$ & $96.6 \%$ \\
\hline Female & $94.7 \%$ & $96.6 \%$ & $94.2 \%$ & $97.5 \%$ \\
\hline Difference & $-1.6 \%$ & $1.5 \%$ & $-1.2 \%$ & $-0.8 \%$ \\
\hline Significance of difference & n.s. & n.s. & n.s. & n.s. \\
\hline Enrolment rate (15-18 years) & $74.8 \%$ & $85.2 \%$ & $68.6 \%$ & $79.2 \%$ \\
\hline Male & $72.4 \%$ & $87.1 \%$ & $69.2 \%$ & $77.0 \%$ \\
\hline Female & $77.2 \%$ & $83.1 \%$ & $67.9 \%$ & $81.6 \%$ \\
\hline Difference & $-4.8 \%$ & $4.0 \%$ & $1.3 \%$ & $-4.5 \%$ \\
\hline Significance of difference & n.s. & n.s. & n.s. & n.s. \\
\hline Enrolment rate (19-21 years) & $36.4 \%$ & $54.0 \%$ & $38.9 \%$ & $55.1 \%$ \\
\hline Male & $39.7 \%$ & $55.8 \%$ & $40.5 \%$ & $59.2 \%$ \\
\hline Female & $33.3 \%$ & $52.0 \%$ & $37.2 \%$ & $50.9 \%$ \\
\hline Difference & $6.4 \%$ & $3.8 \%$ & $3.3 \%$ & $8.4 \%$ \\
\hline Significance of difference & n.s. & n.s. & n.s. & n.s. \\
\hline
\end{tabular}

${ }^{* * *}$-Statistically significant at $\alpha=1 \%,{ }^{* *}$-Statistically significant at $\alpha=5 \%,{ }^{*}$-Statistically significant at $\alpha=10 \%$ and n.s.- Not statistically significant.

Although we have seen that the girls enrolment rates in Table 13 across different age groups are sometime higher than that of boys, when it comes to provide girls with quality education that comes at cost from a private school $^{51}$ then there exist a differential treatment. We find evidences of gender discrimination in selecting the type of schools by the parents for their boys and girls in Mumbai and Delhi. Typically, private (most often English Medium and costly) schools are preferred for the boys, while the girls are more likely to join government (vernacular language and quasi-free) schools. We find statistically significant lower enrolment of girls in private schools than the boys in the slums of Mumbai and Delhi; strikingly, this difference is highest among the Delhi RR residents. This phenomenon perhaps is a typical revelation of a patriarchal mind set, and is a reflection of a consideration of boys' better education as an investment for the future security of the family, while

51 A popular perception among the slum dwellers, also common among the middle class urban dwellers, is that private schools are better than the government schools. 
that of girls' is not (rather a liability). ${ }^{52}$ Perhaps girls, being higher or lower educated, are not expected to monetarily contribute significantly to the family income, be it in parents house or in inlaws place, and that is reflected in their significantly low labour force participation rate (vis-à-vis men) in all the three cities.

\section{Table 14: Some Schooling Characteristics for Students in 6-14 Year Age Group in Slums of Three Cities}

\begin{tabular}{|c|c|c|c|c|}
\hline Type of institution & Kolkata & Mumbai & Delhi JJ & Delhi RR \\
\hline Government institutions & $55.4 \%$ & $38.1 \%$ & $81.9 \%$ & $64.0 \%$ \\
\hline Male & $54.7 \%$ & $33.8 \%$ & $79.8 \%$ & $57 \%$ \\
\hline Female & $56.6 \%$ & $43.0 \%$ & $85.6 \%$ & $72 \%$ \\
\hline Gender difference significance $(95 \%)$ & N.S. & $*$ & $*$ & $*$ \\
\hline Private institutions & $39.7 \%$ & $56.8 \%$ & $14.4 \%$ & $34.2 \%$ \\
\hline Male & $41.4 \%$ & $61.9 \%$ & $16.8 \%$ & $39.7 \%$ \\
\hline Female & $37.8 \%$ & $50.8 \%$ & $10.4 \%$ & $27.9 \%$ \\
\hline Gender difference significance $(95 \%)$ & N.S. & $*$ & $*$ & $*$ \\
\hline Median Distance to government institutions (minutes) & 15 & 10 & 15 & 10 \\
\hline Median Distance to private institutions (minutes) & 15 & 15 & 15 & 10 \\
\hline Provision of mid-day meals & $35.6 \%$ & $25.1 \%$ & $68.6 \%$ & $51.0 \%$ \\
\hline Mid-day meals in $\%$ of govt. inst. & $64.2 \%$ & $66.0 \%$ & $83.7 \%$ & $79.7 \%$ \\
\hline
\end{tabular}

Quite interestingly, although the level of per-capita expenditure and per-capita income are not quite different in slums of Kolkata and in Delhi, the tendency to attend government schools are much higher in Delhi. What may be the cause for this larger preference of private institutions in Delhi? We look at two further characteristics. One is the median distance to schooling and the other is the provision of mid-day meals. The median of reported distances to schools are very similar across cities. The median ranges between 10-15 minutes. We do not find any striking difference across cities. The other characteristic, the provision of mid-day meals however reveals an interesting difference. Nearly $80 \%$ students in Delhi slums who are attending government schools receive mid-day meals; whereas the proportion of such students ranges between 64-66\% in slums of Kolkata and Delhi.

\section{Employment and Earning}

Slums in big cities are ghettos of hapless urban poor who earn much lower average income compared to the rest of the city. One reason for earning lower levels of income may be attributed to their engagement in low-profile occupations, which may be strongly associated with their low levels of human capital (i.e. the lack of education, skills and good health). Moreover, the situation of the slum dwellers are aggravated by continuous influx of unskilled migrants that create a supply of unskilled labour force that often exceeds the demand. This competition keeps wages stagnated at the subsistence level. In this section, we try to explore: What types of occupations do slum dwellers do?

\footnotetext{
52 Typically, the boys, even after their marriage, are expected to look after their parents in older age, while the girls after
} marriage are no more considered to be part of parents' family. 
What types of job contracts do they have? Do the type of jobs and job contracts differ within slums across cities? In this brief section, we present (i) the labour force participation rates and (ii) the type of job contracts that the slum dwellers have. We also look at average years of education and the average levels of income earned. Incidentally, we find that most of the slum dwellers are employed in the informal sectors and merely earn paltry compensation.

The first aspect that we look at is labour force participation rates (hereafter LFPR) among the slum dwellers, especially across age groups and across gender. According to the Census of India, people in the age-group of 15-64 years are considered to form the labour force of the country. The LFPR in urban slums has increased from $35.5 \%$ (54.1\% for males and $15.4 \%$ for females) in 2001 to $46.6 \%$ (65.8\% for males and $27.7 \%$ for females) in 2011 (GoI, 2011). In Table 15, we report the LFPRs among male and female slum dwellers across different age-groups obtained from our survey. ${ }^{53} \mathrm{We}$ observe similar pattern within all three cities. We notice that between $45-50 \%$ of slum dwellers in 15 64 age-group participates in the labour force. The participation rates however vary widely across different age-groups. We divide the age-groups in three sub-groups: 15-18, 19-21 and 22-64. The LFPR among the adult males in 22-64 age-group is highest: $85-88 \%$ of adult males in this age-group in all cities participate in the labour market. The LFPRs in age-groups 15-18 and 19-21 are much lower (statistically significantly) as many adults in these age-groups are pursuing education, which may be verified from Table 13 in the previous section.

Unfortunately, a wide difference across gender is consistently observed in all three cities, where not only LFPRs among females are much lower but also their average monthly earning. We may say that female slum dwellers are less economically active than their male counterparts. The LFPRs among adult males in 15-64 age-groups in all cities are more than $70 \%$ but the same among females are less than $25 \%$. The average monthly earning of females, who participate in the labour market in the agegroup of $15-64$, is only $50-60 \%$ of the average income earned by the males in the same age-group. Are these differences in LFPRs and average earnings due to lower levels of education among females? Kumar and Aggarwal (2003, pp.5296) noted that the lower LFPR among females could be attributed to their lower levels of education resulting in a higher probability of remaining unemployed. We do not however find this perception to be completely true. Even higher average education does not ensure higher average monthly earning for females. If we focus on those participating in the labour market in the age-groups of 19-21, we observe that despite higher average years of education, females in Kolkata and in Delhi's RR colonies do not earn higher average income (differences are statistically insignificant) than their male counterparts. In Mumbai and in Delhi's JJ

\footnotetext{
${ }^{53}$ We mainly report the primary occupation of the slum dweller rather than the secondary occupation.
} 
clusters, despite having no statistically significant differences in average years of education, females in the 15-21 age group earn statistically significantly less average income.

Table 15: Labour Force Participation Rates, Average Years of Education and Average Incomes across Age-groups and Genders in Slums of Three Cities

\begin{tabular}{|c|c|c|c|c|c|c|c|c|c|c|c|}
\hline \multirow{2}{*}{$\begin{array}{l}\text { Age Group and } \\
\text { Gender }\end{array}$} & \multicolumn{2}{|l|}{ Kolkata } & \multicolumn{3}{|c|}{ Mumbai } & \multicolumn{3}{|c|}{ Delhi JJ } & \multicolumn{3}{|c|}{ Delhi RR } \\
\hline & $\begin{array}{c}\text { LFPR AYE } \\
(\%)\end{array}$ & AI & $\begin{array}{c}\text { LFPR } \\
(\%)\end{array}$ & AYE & AI & $\begin{array}{c}\text { LFPR } \\
(\%)\end{array}$ & AYE & AI & $\begin{array}{c}\text { LFPR } \\
(\%)\end{array}$ & AYE & AI \\
\hline ge: $15-64$ & 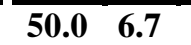 & 6,570 & 48.4 & 9.2 & 10,708 & 48.8 & 5.6 & 7,573 & 44.2 & 8.7 & 11,063 \\
\hline Male & $\begin{array}{ll}76.8 & 6.8\end{array}$ & 7,394 & 72.2 & 9.4 & 11,998 & 71.1 & 6.2 & 8,404 & 70.5 & 9.0 & 12,079 \\
\hline Female & $22.1 \quad 6.0$ & 3,667 & 23.8 & 8.3 & 6,663 & 24.1 & 3.7 & 4,859 & 16.8 & 7.4 & 6,616 \\
\hline Gender Diff & $\begin{array}{ll}* & \text { n.s. }\end{array}$ & $*$ & $*$ & $*$ & $*$ & $*$ & $*$ & $*$ & $*$ & $*$ & \\
\hline Age: & \begin{tabular}{|l|l|}
15.8 & 6.8 \\
\end{tabular} & 3,226 & 5.5 & 8.5 & 3,637 & 12.6 & 6.3 & $\overline{3,411}$ & 10.5 & 8.2 & 4,959 \\
\hline Male & $\begin{array}{ll}24.2 & 6.3\end{array}$ & 3,374 & 5.7 & 8.2 & 4,553 & 17.8 & 6.5 & $\overline{3,821}$ & 16.9 & 8.1 & $\overline{5,291}$ \\
\hline Female & $\begin{array}{ll}7.1 & 8.2 \\
\end{array}$ & 2,729 & 5.3 & 8.9 & 2,560 & 7.1 & 5.8 & 2,335 & 3.5 & 8.7 & 3,185 \\
\hline Gender Diff & n.s. & $n . s$. & n.s. & n.s. & $n . s$. & $*$ & n.s. & * & $*$ & n.s. & n.s. \\
\hline Age: 19- & \begin{tabular}{|l|l|}
33.0 & 8.1 \\
\end{tabular} & 3,360 & 24.4 & 10.8 & 6,253 & 35.5 & 7.2 & 5,065 & 18.1 & 10.0 & 7,263 \\
\hline & 57.0 & $\overline{506}$ & 33.8 & 10.9 & 6,604 & 50.8 & 7.1 & 49 & 30.0 & 9.2 & $\overline{7,714}$ \\
\hline & $\begin{array}{ll}10.9 & 10.4\end{array}$ & 2,703 & 14.4 & 10.7 & 5,377 & 19.9 & 7.6 & 4,064 & 5.9 & 14.2 & 4,886 \\
\hline Gender Diff & $* \quad *$ & n.s. & $*$ & n.s. & $n . s$. & $*$ & n.s. & * & $*$ & $*$ & n.s. \\
\hline Age: 15-21 & $22.7 \quad 7.5$ & 3,304 & 14.2 & 10.3 & 5,708 & 21.7 & 6.9 & $4,486$. & 14.0 & 9.2 & 6,309 \\
\hline Male & 37.1 & 3,453 & 18.6 & 10.4 & 6,264 & 30.8 & 6.8 & 4,878 & 22.7 & 8.7 & 6,709 \\
\hline Female & 8.7 & 2,715 & 9.5 & 10.2 & 4,540 & 12.2 & 7.0 & 3,460 & 4.6 & 11.9 & 4,185 \\
\hline Gender D & $*$ & n.s. & $*$ & n.s. & $*$ & $*$ & n.s. & * & $*$ & $*$ & \\
\hline Age: 22-64 & $\begin{array}{|ll|}57.3 & 6.6 \\
\end{array}$ & 6,909 & 57.5 & 9.1 & 11,035 & 59.8 & 5.4 & 8,023 & 52.9 & 8.7 & 11,425 \\
\hline & $87.0 \quad 6.8$ & 7,814 & 86.6 & 9.4 & 12,331 & 86.5 & 6.1 & 8,886 & 84.6 & 9.0 & 12,503 \\
\hline Female & $25.9 \quad 5.7$ & 3,756 & 27.5 & 8.2 & 6,851 & 29.2 & 3.2 & 5,107 & 20.2 & 7.1 & 6,772 \\
\hline Gender Diff & $*$ & & $*$ & $*$ & * & $*$ & $*$ & * & $*$ & $*$ & \\
\hline Age: 65 \& More & \begin{tabular}{|ll}
21.9 & 4.9 \\
\end{tabular} & 5,377 & 18.4 & 4.9 & 6,645 & 33.7 & 2.5 & 7,027 & 14.0 & 4.1 & 9,105 \\
\hline & $32.0 \quad 6.0$ & & 26.8 & 5.8 & 7,770 & 53.9 & 3.1 & 7,892 & 23.7 & 4.8 & 10,420 \\
\hline & $11.4 \quad 1.9$ & 2,454 & 10.9 & 2.9 & 4,147 & 12.5 & 0.0 & 3,318 & 4.9 & 1.0 & 3,212 \\
\hline Gender Diff & $*$ & $*$ & * & $*$ & $*$ & $*$ & * & * & * & n.s. & \\
\hline
\end{tabular}

LFPR: Labour Force Participation Rate, AYE: Average Years of Education, AI: Average Monthly Income in INR. Note: Rupee figures are adjusted for inter city differences in CPI for various months of survey (base: Delhi October 2014 for Industrial Workers). If the cell corresponding to gender difference has a '*', then this means that the gender difference of that variable is statistically significant at $5 \%$ critical value and 'n.s.' implies that the corresponding difference is not statistically significant.

Although the overall LFPRs and gender-wise differences in LFPRs are similar across slums and across different age groups, there are two particular differences that are worth noting. First, the LFPRs among the young males are higher in slums of Kolkata and Delhi. The LFPR among 15-18 years old males in Kolkata slums are several times higher than that in Mumbai slums. More than 50\% of males in Kolkata slums and in JJ clusters in 19-21 age-group participate in the labour force. This higher (or lower) LFPR is directly linked to the lower (or higher, respectively) educational enrolment rates in Kolkata slums and in JJ clusters in these two age-groups. Second, in the age-group above 64, we observe a stark difference in LFPR between Delhi's JJ cluster and other cities. In Delhi's JJ clusters, $53.9 \%$ of males continue to participate in the labour market, whereas in Kolkata, Mumbai and Delhi's RR colonies, a substantially lower percentage of males (23-32\%) remain active. 
Let us delineate the issues raised under the first point above. Among the age groups of 15-18 and 1921 years, when we look at the participation rate and their corresponding average years of schooling at the gender level in this subgroup, some interesting facts come up. There is an inverse relationship between the LFPR and average years of schooling in these groups as these are the people supposed to be in School/ College till the age 18 (or 21) to complete $12^{\text {th }}$ standard (or an under-graduation degree, respectively). If someone continues to remain in educational institution, his/her participation in the workforce is deferred. An early school dropout person tries to get employed much ahead of others and that is quite eminent here. Young males' LFPRs are consistently much higher than those of young females (except in Mumbai slums for the age group of 15-18). However, young male workers do not imbibe higher education levels vis-à-vis young female workers (as the differences are not statistically significant). Young females in general before joining workforce stay back in schools for more years than their male counter parts in these age groups. In Delhi JJ however situation is different, female dropout rate is very high even before grade VIII and at the same time majority of them are not allowed to go for work outside the home. But, young females' LFPR is governed by many other factors such as marriage prospects and cultural barriers. Women are often discriminately expected to deal with domestic chores when they stop going to educational institutions and look after children when they get married.

One important point in terms of inter-generational educational attainment of the workforce that is visible in Kolkata among male workers is that there is no statistically significant difference in the average levels of schooling for males in the age group of 65 and higher and for males in the age group of 22-64. In other cities however the average years of schooling among 22-64 years old males are statistically significantly higher, Thus, the average years of schooling somewhat stagnates between six and seven years in Kolkata for male workers. This observation calls for further research in future. A positive observation is that the average years of education among women workers reflect statistically significant increase in all cities.

\section{Job Conditions and Security}

We now highlight on the type of job contract that the slum dwelling employees have. In Table 16, we present the percentage of working slum dwellers, average years of education completed, average monthly nominal wage and average weekly labour supply under different types of job contracts. An overwhelming majority of working slum dwellers are involved in informal jobs. In Kolkata 77.4\%, in Mumbai 62.3\%, in Delhi JJ clusters 89.5\% and in Delhi RR 76\% of slum dwellers have informal jobs. Employees involved in informal jobs consistently earn statistically significantly lower average nominal wages across all cities; whereas employees involved in government jobs supply statistically significantly less labour weekly (in hours) across all cities. 
Table 16: Education, Wage and Labour Supply by Type of Job Contracts

\begin{tabular}{lrrr}
\hline & Informal \\
Type of Job Contract & & $\begin{array}{r}\text { Contractual } \\
\text { Jobs }\end{array}$ & $\begin{array}{r}\text { Govt. } \\
\text { Jobs }\end{array}$ \\
\hline Kolkata & & & \\
\hline Share involved in occupation (\%) & 77.4 & 15.5 & 5.6 \\
Average years of education completed & 6.0 & 8.8 & 9.0 \\
Average monthly nominal wage (in INR) & 5780 & 7962 & 14170 \\
Average weekly labour supply (in hours) & 58 & 62 & 46 \\
\hline Mumbai & & & \\
\hline Share involved in occupation (\%) & 62.3 & 30.2 & 7.0 \\
Average years of education completed & 8.2 & 10.7 & 10.7 \\
Average monthly nominal wage (in INR) & 9695 & 11134 & 18339 \\
Average weekly labour supply (in hours) & 59 & 60 & 51 \\
\hline Delhi JJ & & & \\
\hline Share involved in occupation (\%) & 89.5 & 6.2 & 4.1 \\
Average years of education completed & 5.4 & 8.6 & 6.0 \\
Average monthly nominal wage (in INR) & 7089 & 9860 & 14798 \\
Average weekly labour supply (in hours) & 58 & 60 & 52 \\
\hline Delhi RR & & & \\
\hline Share involved in occupation (\%) & 76.0 & 14.9 & 8.8 \\
Average years of education completed & 8.3 & 10.6 & 9.3 \\
Average monthly nominal wage (in INR) & 9565 & 12482 & 21651 \\
Average weekly labour supply (in hours) & 59 & 59 & 50 \\
\hline Note: Rupee figures are adjusted for inter city differences in CPI for various months of survey (base: Delhi October \\
2014).
\end{tabular}

\section{Discussions and Concluding Remarks}

In this paper, we have presented descriptive results comparing the standard of living within slums across three cities of India - Kolkata, Mumbai and Delhi. Based on our collected samples, we find certain slum-characteristics are common across three cities. The average household size within slums of all three cities ranges between 5-5.5 members per household and on average there resides 3.3 slum dwellers per sleeping room. In all three cities, majority of the slum dwellers have migrated from neighbouring states than the native state of the city. More than half of the houses are built with some unimproved roof, wall or floor materials, yet $90 \%$ or more households have electricity connection for 18-24 hours as well as at least one person in the household owns a cell phone. The average years of schooling completed by slum dwellers in all three cities do not surpass nine years, but $90 \%$ of children in the age group of 6-14 years are enrolled in schools as well as more than $90 \%$ of the adults in the age group of 15-25 years are literate. Around $90 \%$ of male members in the age group of 25-50 years participate in the labour market, yet nearly two-third or more of the women in the same age group do not. Finally, we find that inequality levels both in terms of per capita incomes and per capita consumption expenditures within slums across these three cities are very similar.

Despite a number of similar characteristics, however, slums in different cities have an even larger number of differences. The first set of differences is noticed in their demographic structures. Slums in Kolkata are much older than those in both Mumbai and Delhi. This fact is reflected both in terms of 
the proportion of slum dwellers born in the city and the duration of the constructions within slums. In Kolkata, more than $60 \%$ of household heads in slums were born in the city and nearly $70 \%$ of the constructions are older than 30 years. In Delhi, on the other hand, only a quarter of the household heads were born in the city and merely $20 \%$ of all constructions in slums are older than 30 years. Although the slums and the constructions within them are much older in Kolkata, yet much higher proportion of houses are built with unimproved floor, wall or roof materials, which directly affects the slum dwellers' living conditions.

The second set of differences is observed in the access to facilities such as access to sanitation facilities and access to drinking water. Close to $70 \%$ of the slum dwellers of all three cities depend heavily on publicly provided sanitation facilities in their neighbourhood, but around $31 \%$ of Mumbai slum dwellers and $47 \%$ of Delhi JJ cluster slum dwellers travel more than five minutes to access the facilities. This particular problem is not at all acute in Kolkata slums. Authorities of Delhi and Mumbai should recognize this critical issue and try to improve the access to public sanitation facilities within the slum neighbourhoods, keeping in mind the associated hygiene factor. In terms of access to drinking water, more than $80 \%$ slum dwellers depend on standpipes - personal or non-personal but mainly publicly provided - to fetch drinking water. However, there are crucial differences across cities in terms of personal versus non-personal access, time taken to fetch water from the source, the duration of water availability per day. Mumbai fare much better in providing larger frequency of personal as well as non-personal facilities that reduces the time to fetch water. Attention should be paid to those more than 9\% of slum dwellers in Kolkata and Delhi who still access to non-improved drinking water sources.

The third set of major differences is visible in education achievements and labour market participations of the slum dwellers. The adult literacy rate within Mumbai slums is nearly $90 \%$, whereas the adult literacy rate in squatters of Delhi is only $70 \%$. A characteristic that is markedly unique to slums in Delhi is the large difference in adult literacy rate across genders. In squatters of Delhi less than half of the adult women are illiterate in the age group of 25-50 years and more than $80 \%$ are illiterate in the age group of 50 years or more. Among children, although the school enrolment rate among the 6-14 years age group is more than $90 \%$ in all cities, majority of the students in Delhi slums appear to attend public school but majority of the students in Mumbai appear to attend private schools. Relatedly, nearly $80 \%$ of the students in the same age group in public schools receive mid-day meal in Delhi, but the corresponding proportion is between only 64-66\% in both Kolkata and Mumbai.

The study of living conditions of the slum dwellers remains incomplete without looking at their incomes and consumption expenditures, which we summarize in the fourth set of differences. The 
higher level of education and better earning opportunities in Mumbai definitely influence the average monthly earnings of the slum dwellers. We find the monthly average per capita nominal income in slums of Mumbai appears to be $73 \%$ higher than that in Kolkata. The monthly average nominal income is thus highest in slums of Mumbai followed by the slums in Delhi and then Kolkata. The higher average earning is also reflected in higher monthly average nominal per capita consumption expenditures across slums. The decomposition of the overall per capita consumption expenditure however reveals certain crucial differences. For example, although the overall per capita expenditure is statistically significantly higher in Delhi slums, there is no statistically significant difference in per capita food expenditures. The per capita expenditure on grocery items is in fact significantly lower in Delhi slums than in Kolkata slums due to the provision of groceries through public distribution systems. We also observe several other differences in the composition of consumption expenditures in slums across cities that purely arise from strong differences in the collective preferences of slum dwellers.

Differences are observed also in the use of cooking fuel across cities. We have found that $87 \%$ of all households in Mumbai and more than $94 \%$ of households in Delhi have adopted liquid petroleum gas (LPG) as cooking fuel; whereas in Kolkata slums only $47 \%$ of households use LPG. In fact, $95 \%$ of slum dwellers use Kerosene, despite Kerosene having various health hazards. Mumbai and Delhi have gone through a transition where Kerosene users have switched to become much safer and environment friendly liquid petroleum gas (LPG) users. Residents in Mumbai slums have bore the cost of a LPG connection themselves; whereas the Delhi government has paid a subsidy (for an LPG cylinder and stove) to all the PDS cardholders to convert them from being Kerosene users to LPG users. The state government in Kolkata unfortunately continues to provide kerosene through its public distribution system at a subsidized rate. There may be several reasons behind the pursuance of this policy, but given the hazards the Kerosene uses face this policy should be scrutinized.

What we may conclude from our findings in this paper is that on average, living conditions in slums of Kolkata and Delhi's JJ clusters are worse than that in slums of Mumbai and Delhi's RR colonies. What do the slum dwellers think of their own living conditions? During our surveys, we asked the respondents how satisfied they were with the living conditions of their households, providing three choices: very dissatisfied, not satisfied and satisfied. Around 70 percent of all households in Mumbai and Delhi's RR colonies responded that they were satisfied with living conditions; whereas around half of all households in Kolkata and Delhi's JJ clusters responded that they were either not satisfied or very dissatisfied with their living conditions. This subjective well-being question matches with our objective findings of living conditions. 


\section{References}

Banerjee, A., R. Pande, Y. Vaidya, M. Walton, and J. Weaver (2011). Delhi's Slum-Dwellers: Deprivation, Preferences and Political Engagement among the Urban Poor. In International Growth Centre Conference proceedings (Growth Week 2011).

Basu, A. R. (1988), Urban Squatter Housing in Third World, Delhi: Mittal Publication.

Census of India (2013), 2011 Primary census abstract for slum, New Delhi: Office of the Registrar General \& Census Commissioner.

de Soto, H. (2003), Hearing the dogs bark, Finance and Development, 40(4), 3-11.

Deaton, A. (1997). The analysis of household surveys: a microeconometric approach to development policy. World Bank Publications.

Furedy, C. (1982), Whose responsibility? Dilemmas of Calcutta's bustee policy in the nineteenth century. Journal of South Asian Studies, 5(2), 24-46.

Government of Delhi (2006), City Development Plan Delhi, New Delhi: Department of Urban Development.

Government of India (2010), Report of the Committee on Slum Statistics/Census, Ministry of Housing and Urban Poverty Alleviation, New Delhi: National Buildings Organisation.

Government of India (2011), Report of The Working Group on Urban Poverty, Slums, and Service Delivery System, Steering Committee on Urbanization, Planning Commission, New Delhi.

Hina (2013), Poorest of the Poor: A Comparative Study of Two Slums of Central and North East Delhi, India, Global Advanced Research Journal of Geography and Regional Planning, Vol. 2(5), 8796.

Kumar, N., and Aggarwal, S. C. (2003). Patterns of consumption and poverty in Delhi slums. Economic and Political Weekly, 5294-5300.

Kundu, A. and N. Sarangi (2007), Migration, Employment Status and Poverty: An Analysis across Urban Centres, Economic and Political Weekly, Vol. 42, No. 4, 299-306

Kundu, N. (2003), The case of Kolkata, India, in UN-Habitat (Ed.), Cities without slums: Global report on human settlements (Earthscan).

Lucci, P. and T. Bhatkal (2014), Monitoring progress on urban poverty: are current data and indicators fit for purpose?, Working Paper 405, Overseas Development Institute, London.

Mallik S. (2014), Gender Inequality in Literacy and School Level Education in Slums of Kolkata Municipal Corporation, India, International Research Journal of Social Sciences, Vol. 3(11), 27-33.

Marx, B., T. Stoker, and T. Suri (2013). The economics of slums in the developing world. The Journal of Economic Perspectives, 187-210. 
Mitra, Arup (2005), Living Standard In Delhi Slums: Consumption Expenditure, Housing And Ability To Save, The Indian Journal of Labour Economics, Vol. 48(3).

Moitra, M.S. (1991), Shelter: Slums and Squatter Settlements' in Calcutta's Urban Future: Agonies from the Past and Prospects for the Future, Calcutta: South Asia Books.

Mullera, E., R.D. Diabb , M. Binedella , R. Hounsomea (2003), Health risk assessment of kerosene usage in an informal settlement in Durban, South Africa, Atmospheric Environment vol. 37, pp. 2015-2022.

National Council of Applied Economic Research (2002), The burden of ill-health among the urban poor: The case of slums and resettlement colonies in Chennai and Delhi, NCAER, Delhi.

Priya, Ritu (1993). Town Planning, Public Health and Urban Poor: Some Explorations from Delhi. Economic and Political Weekly, 824-834.

Ramaswamy, V., Life in Calcutta's Urban Slums, accessed in May 2015 at http://asiasociety.org/renewing-city-efforts-improve-life-calcutta\%E2\%80\%99s-urban-

slums?page $=0,1$.

Ramaswamy, V. (2008). Basti Redevelopment in Kolkata, EPW, Vol - XLIII No. 38, September, 2008

Ravallion, M. (2002). On the urbanization of poverty. Journal of Development Economics, 68, 435442.

Registrar General of India (2001, 2011), Census of India, Government of India, Delhi

Risbud, N. (2003), The case of Mumbai, India, in UN-Habitat (Ed.), Cities without slums: Global report on human settlements (Earthscan).

Schenk, W. Colin (2010), Slum Diversity in Kolkata, Columbia Undergraduate Journal of South Asian Studies, vol. I(II), 91-108.

Sharma, Kalpana (2000), Rediscovering Dharavi: Stories from Asia's Largest Slum, Penguin Books.

Sheikh, S, Subhadra Banda, and Ben Mandelkern (2014), Planning the Slum: JJC Resettlement in Delhi and the Case of Savda Ghevra. A report of the Cities of Delhi project, Working Paper, Centre for Policy Research, New Delhi.

Singh, Pratima (2009), Sheltering Delhi's Slums, Working Paper No. 230 at Centre for Civil Society, Delhi, India.

Swaminathan, M. (1995). Aspects of urban poverty in Bombay. Environment and Urbanization, 7(1), 133-144.

The Nossal Institute for Global Health (2011), Asha: Hope and Transformation in the Slums of Delhi, Australia India Institute, The University of Melbourne.

United Nations Human Settlements Programme (UN-Habitat) (2003), The Challenge of Slums: Global Report on Human Settlements, Earthscan Publications Ltd, VA: London and Sterling. 
United Nations Human Settlements Programme (2012), State of the World's Cities 2012/2013: Prosperity of Cities, Nairobi, Kenya.

United Nations Human Settlements Programme (UN-Habitat) (2014), Land Tenure Security In Selected Countries: Synthesis Report, HS Number: HS/039/14E 


\section{Appendix A: The distribution of sample household across different strata in Three} Cities

\begin{tabular}{|c|c|c|c|c|c|}
\hline \multicolumn{6}{|c|}{ Kolkata (808 Sample Households) } \\
\hline Borough 1 & 31 & Borough 6 & 86 & Borough 11 & 31 \\
\hline Borough 2 & 30 & Borough 7 & 194 & Borough 12 & 68 \\
\hline Borough 3 & 47 & Borough 8 & 32 & Borough 13 & 30 \\
\hline Borough 4 & 30 & Borough 9 & 44 & Borough 14 & 44 \\
\hline Borough 5 & 31 & Borough 10 & 30 & Borough 15 & 80 \\
\hline \multicolumn{6}{|c|}{ Mumbai (1,228 Sample Households) } \\
\hline Ward A & 33 & Ward HE & 76 & Ward PN & 87 \\
\hline Ward B & 11 & Ward HW & 31 & Ward PS & 43 \\
\hline Ward D & 31 & Ward KE & 78 & Ward RC & 31 \\
\hline Ward E & 30 & Ward KW & 59 & Ward RN & 30 \\
\hline Ward FN & 55 & Ward L & 110 & Ward RS & 55 \\
\hline Ward FS & 30 & Ward ME & 94 & Ward S & 106 \\
\hline Ward GN & 54 & Ward MW & 49 & Ward T & 30 \\
\hline Ward GS & 34 & Ward N & 71 & & \\
\hline \multicolumn{6}{|c|}{ Delhi Jhuggi Jhopri (864 Sample Households)* } \\
\hline $\mathrm{DCN}$ & 83 & DNO & 105 & DSO & 120 \\
\hline DES & 45 & DNW & 80 & DSW & 46 \\
\hline DNE & 30 & DSE & 56 & DWS & 137 \\
\hline DNN & 77 & DSH & 85 & & \\
\hline \multicolumn{6}{|c|}{${ }_{\text {Delhi Relocation and Resettlement (431 Sample Households) }}^{*}$} \\
\hline$\overline{\mathrm{DCN}}$ & 14 & DNW & 160 & DWS & 82 \\
\hline DES & 44 & DSO & 44 & & \\
\hline DNE & 54 & DSW & 33 & & \\
\hline
\end{tabular}

\section{Appendix B: Holding Status of Various Government Issued Cards in Slums of Three Cities}

\begin{tabular}{|c|c|c|c|c|}
\hline PDS Cards Holding & Kolkata & Mumbai & Delhi JJ & Delhi RR \\
\hline APL & $84 \%$ & $70 \%$ & $18 \%$ & $34 \%$ \\
\hline BPL & $6 \%$ & $19 \%$ & $30 \%$ & $16 \%$ \\
\hline Antyodaya & $1 \%$ & $0 \%$ & $18 \%$ & $4 \%$ \\
\hline Annapurna & $0 \%$ & $0 \%$ & $1 \%$ & $0 \%$ \\
\hline No Card & $9 \%$ & $6 \%$ & $15 \%$ & $1 \%$ \\
\hline Old Card & - & $2 \%$ & $1 \%$ & $26 \%$ \\
\hline \multicolumn{5}{|c|}{ Voter Id Status for Adults } \\
\hline Male & $85.7 \%$ & $82.8 \%$ & $84.0 \%$ & $93.8 \%$ \\
\hline Female & $81.6 \%$ & $76.4 \%$ & $79.9 \%$ & $89.1 \%$ \\
\hline Over All & $83.7 \%$ & $79.7 \%$ & $82.1 \%$ & $91.5 \%$ \\
\hline Non-migrant & $82.8 \%$ & $76.2 \%$ & $72.9 \%$ & $90.4 \%$ \\
\hline Migrant & $87.3 \%$ & $85.9 \%$ & $90.2 \%$ & $93.5 \%$ \\
\hline Aadhar Registered & $79 \%$ & $94 \%$ & $95 \%$ & $98 \%$ \\
\hline
\end{tabular}

